\title{
Hyperexcitability of Rat Thalamocortical Networks after Exposure to General Anesthesia during Brain Development
}

\author{
Michael R. DiGruccio, ${ }^{1,2}$ Srdjan Joksimovic, ${ }^{1,7}$ Pavle M. Joksovic, ${ }^{1}$ Nadia Lunardi, ${ }^{1}$ Reza Salajegheh, ${ }^{1}$ \\ Vesna Jevtovic-Todorovic, ${ }^{1,2,4}$ Mark P. Beenhakker, ${ }^{2,6} \mathbb{C}_{\text {Howard P. Goodkin, }, 3,3,5}$ and Slobodan M. Todorovic ${ }^{1,2,4}$ \\ ${ }^{1}$ Department of Anesthesiology, ${ }^{2}$ Neuroscience Graduate Program, Departments of ${ }^{3}$ Neurology, ${ }^{4}$ Neuroscience, ${ }^{5}$ Pediatrics, and ${ }^{6}$ Pharmacology, University \\ of Virginia School of Medicine, Charlottesville, Virginia 22908, and 7Department of Pharmacology, Faculty of Pharmacy, University of Belgrade, Belgrade, \\ Serbia
}

Prevailing literature supports the idea that common general anesthetics (GAs) cause long-term cognitive changes and neurodegeneration in the developing mammalian brain, especially in the thalamus. However, the possible role of GAs in modifying ion channels that control neuronal excitability has not been taken into consideration. Here we show that rats exposed to GAs at postnatal day 7 display a lasting reduction in inhibitory synaptic transmission, an increase in excitatory synaptic transmission, and concomitant increase in the amplitude of T-type calcium currents (T-currents) in neurons of the nucleus reticularis thalami (nRT). Collectively, this plasticity of ionic currents leads to increased action potential firing in vitro and increased strength of pharmacologically induced spike and wave discharges in vivo. Selective blockade of T-currents reversed neuronal hyperexcitability in vitro and in vivo. We conclude that drugs that regulate thalamic excitability may improve the safety of GAs used during early brain development.

Key words: anesthesia; GABAA receptor; glutamate; low-voltage-activated; T-channels; thalamus

\section{Introduction}

Every year tens of millions of patients, including very young children, are exposed to general anesthetics (GAs); however, recent studies have shown that common GAs may harm the developing mammalian brain (for review, see Jevtovic-Todorovic and Olney, 2008). Various classes of GAs can trigger widespread neurodegeneration in developing rodent and nonhuman primate brains, including in the thalamus (Jevtovic-Todorovic et al., 2003; Brambrink et al., 2010; Zou et al., 2011). A recent population-based study showed that early exposure to GAs is a significant risk for later learning disability in children (Wilder et al., 2009). Thus, further research into cellular mechanisms of action of currently available GAs and development of suitable neuroprotective drugs is warranted, especially to improve safety of GAs in children.

The thalamic nuclei are important in awareness and cognitive functions (Steriade et al., 1990; Sherman, 2005). T-type calcium channels (T-channels) are critically important in the control of cellular excitability and in the generation of rhythmic oscillations between mutually interconnected cortical (Ctx) and thalamocor-

Received Nov. 20, 2013; revised Nov. 16, 2014; accepted Nov. 22, 2014.

Author contributions: V.J.-T., H.P.G., and S.M.T. designed research; M.R.D., S.J., P.M.J., and N.L. performed research; M.R.D., S.J., P.M.J., R.S., M.P.B., H.P.G., and S.M.T. analyzed data; M.R.D. and S.M.T. wrote the paper.

This work was supported in part by National Institutes of Health Grants HD-044517 to V.J.-T., GM-102525 to S.M.T., March of Dimes to V.J.-T., NS-067439 to H.P.G., and the Department of Anesthesiology at University of Virginia. We thank Dr. Karthik Rajasekaran and Dr. Mark Conaway for help with data analysis; Drs. S. Mennerick, J. Sando, Veit-Simon Eckle, and D. Bayliss for critical reading of the manuscript; and Dr. V. N. Uebele (Merck Research Laboratories, West Point, PA), for kindly providing TTA-P2.

The authors declare no competing financial interests.

Correspondence should be addressed to Dr. Slobodan M. Todorovic, Department of Anesthesiology, University of Virginia Health System, Mail Box 800710, Charlottesville, VA 22908-0710. E-mail: st9d@virginia.edu.

DOI:10.1523/JNEUROSCI.4883-13.2015

Copyright $\odot 2015$ the authors $\quad 0270-6474 / 15 / 351481-12 \$ 15.00 / 0$ tical (TC) relay neurons in the ventrobasal (VB) thalamic nucleus and nucleus reticularis thalami (nRT), a main inhibitory structure in the thalamus. It is well established that these oscillatory patterns are important for normal sensory processing, attention, transitions from sleep and awake states, and anesthesia; and they also may contribute to many brain disorders, including absence seizures (Steriade et al., 1990; Llinás et al., 2005; Sherman, 2005). However, the chronic effects of exposure to GAs during critical periods of brain development on the function of the major groups of ion channels that control excitability in TC networks are not well studied. Our previous study established that a common volatile general anesthetic, such as isoflurane (Iso), causes dose-dependent $(0.75,1.0$, or 1.5 vol\%) neurodegeneration in various regions of brain in rat pups and that thalamic nuclei are severely affected (Jevtovic-Todorovic et al., 2003). Furthermore, when a low toxic dose of Iso $(0.75 \mathrm{vol} \%)$ was combined with a nontoxic dose of midazolam $(9 \mathrm{mg} / \mathrm{kg}$, i.p.) and nontoxic dose of nitrous oxide $\left(\mathrm{N}_{2} \mathrm{O}\right)$ of $75 \mathrm{vol} \%$, this triple mixture resulted in robust neurodegeneration entailing severe damage to the thalamus and parietal cortex, and also producing moderate to severe damage in many other brain regions (Jevtovic-Todorovic et al., 2003). Hence, we tested the hypothesis that exposure of rat pups to the triple mixture may cause functional alterations in TC circuitry. Here, we show that exposure of rat pups at postnatal day 7 (P7) to a clinically relevant anesthetic mixture consisting of midazolam, Iso, and $\mathrm{N}_{2} \mathrm{O}$ triggers plasticity of synaptic and intrinsic ion channels in nRT neurons. This, in turn, contributes to lasting hyperexcitability in TC networks that can be curtailed by selectively inhibiting the function of T-type channels. Hence, drugs that regulate neuronal excitability may be useful as novel 
therapeutic agents to reverse lasting effects of GAs on the function of TC circuitry.

\section{Materials and Methods}

Anesthesia. Young and adolescent Sprague Dawley rats were used for this study. They were housed within the animal facility according to protocols approved by the University of Virginia Animal Care and Use Committee. Treatments of rats adhered to guidelines set forth in the National Institutes of Health Guide for the Care and Use of Laboratory Animals. All efforts were made to minimize animal suffering and to use only the number of animals necessary to produce reliable scientific data.

Both male and female rats were assigned randomly either to experimental or control (sham) groups. At P7, rats in the experimental group were injected with $9 \mathrm{mg} / \mathrm{kg}$ midazolam intraperitoneally and then exposed to $6 \mathrm{~h}$ of a clinically relevant anesthetic combination with $75 \mathrm{vol} \%$ $\mathrm{N}_{2} \mathrm{O}$ and $0.75 \mathrm{vol} \%$ Iso in an atmosphere of $24 \mathrm{vol} \% \mathrm{O}_{2}$. Sham controls were exposed to $6 \mathrm{~h}$ of mock anesthesia consisting of a vehicle injection of $0.1 \%$ DMSO in a chamber with an air atmosphere and separation from their mothers. Midazolam (Sigma-Aldrich) was dissolved in $0.1 \%$ DMSO and was given via an intraperitoneal injection before exposure to volatile anesthetics. A few experiments were performed with $6 \mathrm{~h}$ of anesthesia using $75 \mathrm{vol} \% \mathrm{~N}_{2} \mathrm{O}$ and $0.75 \mathrm{vol} \%$ Iso without midazolam, but results were virtually identical to those that included all three agents. Exposure to $\mathrm{N}_{2} \mathrm{O}, \mathrm{O}_{2}$, and Iso used a dedicated premixer of $\mathrm{N}_{2} \mathrm{O}$ and $\mathrm{O}_{2}$ followed by an agent-specific vaporizer that delivered a defined percentage of Iso into a temperature-controlled chamber preset to maintain $33^{\circ} \mathrm{C}-34^{\circ} \mathrm{C}$. The composition of the gas chamber was analyzed by realtime feedback (Datex Capnomac Ultima) for $\mathrm{N}_{2} \mathrm{O}$, Iso, $\mathrm{CO}_{2}$, and $\mathrm{O}_{2}$ percentages.

Brain slice preparation. Rats (P10-P18) were anesthetized briefly with Iso and decapitated, and their brains were removed rapidly. Live 300$\mu \mathrm{m}$-thick horizontal brain slices were sectioned at $4^{\circ} \mathrm{C}$ in prechilled (in mM) as follows: sucrose 260, D-glucose 10, $\mathrm{NaHCO}_{3} 26, \mathrm{NaH}_{2} \mathrm{PO}_{4} 1.25$, $\mathrm{KCl} 3, \mathrm{CaCl}_{2} 2, \mathrm{MgCl}_{2}$ 2, using a vibrating micro slicer (Ted Pella Instruments DTK 1000). Brain slices were immediately incubated for $45 \mathrm{~min}$ in the following (in mM): $\mathrm{NaCl} 124$, D-glucose 10, $\mathrm{NaHCO}_{3} 26, \mathrm{NaH}_{2} \mathrm{PO}_{4}$ $1.25, \mathrm{KCl} 4, \mathrm{CaCl}_{2} 2, \mathrm{MgCl}_{2} 2$ at $37^{\circ} \mathrm{C}$ before use in electrophysiology experiments, which were done at room temperature. During incubation, slices were constantly perfused with a gas mixture of $95 \mathrm{vol} \% \mathrm{O}_{2}$ and 5 vol $\% \mathrm{CO}_{2}$.

Thalamic brain slices from GA-treated animals contained a smaller number of viable neurons than those from sham-treated rats, consistent with reported massive neurodegeneration in GA-treated rats (JevtovicTodorovic et al., 2003; Boscolo et al., 2012). The decreased number of viable neurons in this heavily reticulated thalamic nucleus made visualization and patch-clamp recordings of nRT neurons in animals older than $\mathrm{P} 18$ practically impossible.

Our in vitro pharmacological experiments are designed to establish proof of concept that blockers of ion channels may reverse GA-induced hyperexcitability of thalamic neurons and to set the stage for ensuing in vivo experiments. Although our method allows investigation of the chronic effects of anesthetic on excitability in intact native neurons, quantitative assessment of the drug effects is limited because delivery of drug-containing solutions in vitro may be compromised due to diffusion through the sliced tissue. The actual concentrations of all drugs at their sites of action are likely to be much lower than those reported.

Electrophysiology experiments. The external solution for current-clamp electrophysiology experiments consisted of the following (in $\mathrm{mm}$ ): $\mathrm{NaCl}$ 125, D-glucose 25, $\mathrm{NaHCO}_{3} 25, \mathrm{NaH}_{2} \mathrm{PO}_{4} 1.25, \mathrm{KCl} 2.5, \mathrm{MgCl}_{2} 1, \mathrm{CaCl}_{2}$ 2. For current-clamp experiments, the internal solution consisted of the following (in mM): potassium-D-gluconate 130, EGTA 5, NaCl 4, $\mathrm{CaCl}_{2}$ 0.5, HEPES 10, Mg ATP 2, Tris GTP 0.5, pH 7.2. The external solution for experiments with synaptic currents and T-currents included the following (in mM): $\mathrm{NaCl} 130, \mathrm{CaCl}_{2} 2, \mathrm{KCl} 2, \mathrm{MgCl}_{2} 1, \mathrm{NaHCO}_{3} 26, \mathrm{NaH}_{2} \mathrm{PO}_{4}$ 1.25 , and D-glucose 10 . This solution was equilibrated with a mixture of 95 vol $\% \mathrm{O}_{2}$ and $5 \mathrm{vol} \% \mathrm{CO}_{2}$ for at least $30 \mathrm{~min}$ with a resulting $\mathrm{pH}$ of $\sim 7.4$. The internal solution for experiments with T-currents consisted of the following (in mM): tetramethyl ammonium-OH 135, EGTA 10, $\mathrm{MgCl}_{2}$ 2, HEPES 40, titrated to $\mathrm{pH} 7.2$ with hydrofluoric acid. For re- cording of IPSCs, we used an internal solution containing the following (in mMm): $\mathrm{KCl} 130, \mathrm{NaCl} 4, \mathrm{CaCl}_{2} 0.5$, EGTA 5, HEPES 10, $\mathrm{MgATP}_{2} 2$, Tris-GTP 0.5, and lidocaine $N$-ethyl bromide (QX-314) 5. pH was adjusted with $\mathrm{KOH}$ to 7.25. For recordings of EPSCs, this internal solution was modified by replacing $\mathrm{KCl}$ with equimolar $\mathrm{K}$-gluconate and external solution contained $0.5 \mathrm{mM} \mathrm{MgCl}_{2}$. Glass microelectrodes (Sutter Instruments, OD $1.5 \mathrm{~mm}$ ) were pulled using a Sutter Instruments model P97 and fabricated to maintain an initial resistance of 4-7 $\mathrm{m} \Omega$. Neuronal membrane responses were recorded using an Axopatch $200 \mathrm{~B}$ amplifier (Molecular Devices). Voltage current commands and digitization of the resulting voltages and currents were performed with Clampex 8.3 software (Molecular Devices) running on PC-compatible computer. Resulting current and voltage traces were analyzed using Clampfit 10.3 (Molecular Devices). Statistical and graphical analyses were performed using GraphPad Prism 5.01 software (GraphPad Software) or Origin 7.0 (OriginLab). Results typically are presented as means from different animals \pm SEM unless stated otherwise.

Current-clamp experiments. Both tonic and burst-firing properties of $\mathrm{nRT}$ neurons were characterized by using multistep protocols with synaptic blockers (20 $\mu \mathrm{M}$ picrotoxin, $50 \mu \mathrm{M} \mathrm{D}-\mathrm{APV}$, and $5 \mu \mathrm{M}$ NBQX) in the external solution. For hyperpolarizing-induced burst firing, nRT neurons were patched in the whole-cell configuration, and resting membrane potentials were recorded for a $100 \mathrm{~ms}$ period that was averaged from at least three consecutive traces. To investigate burst-firing patterns, the neurons were injected with hyperpolarizing currents in $50 \mathrm{pA}$ intervals stepping from -200 to $-500 \mathrm{pA}$. To investigate tonic firing patterns in these cells, we injected a family of depolarizing $(5,10-190 \mathrm{pA})$ current pulses of $500 \mathrm{~ms}$ duration in $10 \mathrm{pA}$ incremental steps through the recording pipette. Subsequent resting membrane potentials, tonic action potential (AP) frequencies, rebound APs, and input resistances were determined.

AP-independent synaptic currents. In the patch-clamp configuration at a holding potential of $-70 \mathrm{mV}$, AP-independent miniature EPSCs (mEPSCs) were isolated in the presence of $1 \mu \mathrm{M}$ TTX to block voltagegated sodium channels and $20 \mu \mathrm{M}$ picrotoxin to block GABA-mediated inhibitory currents. In experiments measuring AP-independent minia-

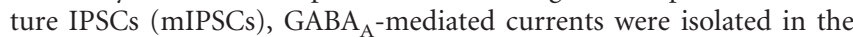
presence of the NMDA channel blocker D-APV $(50 \mu \mathrm{M})$ and AMPA channel blocker NBQX $(5 \mu \mathrm{M})$. All data were analyzed using MiniAnalysis software (Synaptasoft). The limits for mEPSCs and mIPSCs were set in most of recordings at $3 \times$ the root mean square of baseline noise. In our analysis of kinetics of spontaneous synaptic currents, we included only isolated (i.e., nonoverlapping) events. All mIPSCs were analyzed with respect to peak amplitude, and 10\%-90\% rise time and fastest events (rise times $\leq 3 \mathrm{~ms}$ ) were chosen for further analysis of decay time course and half-width. The decay time course of these experiments was fit using a single exponential function.

Cumulative distribution functions. Plots describing the cumulative distribution functions (CDFs) of mEPSC and mIPSC properties (i.e., amplitude, interevent interval [IEI] and half-width) were derived empirically using custom scripts written in MATLAB (MathWorks). In brief, the CDF describes the probability that an event amplitude (or IEI, half-width) will be found that is less than or equal to that event. CDFs were derived for individual neurons as well as for data pooled from all neurons.

Evoked synaptic currents. Evoked synaptic transmission was evaluated by stimulation within the internal capsule, and the responses were recorded within patch-clamped nRT neurons. Synaptic stimulation was achieved using a constant current isolated stimulator $\mathrm{DS}_{3}$ (Digitimeter). Evoked EPSCs (eEPSCs) were recorded within the nRT at a holding potential of $-70 \mathrm{mV}$ in the presence of $20 \mu \mathrm{m}$ picrotoxin. The threshold current stimulus, 50\% maximum, and stimulus for maximum EPSC current amplitude were determined. All excitatory synaptic currents were eliminated if $5 \mu \mathrm{M} \mathrm{NBQX}$ and $50 \mu \mathrm{M}$ D-APV were included in the external solution.

Properties of evoked IPSCs (eIPSCs) were explored using a paired pulse ratio (PPR) stimulus protocol. Electrode stimulus was applied within the internal capsule at an interval of $1 \mathrm{~s}$ at an intensity of $50 \%$ maximum current stimulus. $\mathrm{GABA}_{\mathrm{A}}$-mediated currents were isolated in 
Table 1. Statistical comparisons (GA vs sham) across all in vitro and in vivo analysis ${ }^{a}$

\begin{tabular}{|c|c|c|c|c|c|c|}
\hline & elPSC & mIPSC & eEPSC & mEPSC & $1-0$ & Rebound AP \\
\hline$t$ test (per neuron) & $\begin{array}{l}\tau: p<0.001^{*} \\
\text { PPR: } \boldsymbol{p}=0.001\end{array}$ & $\begin{array}{l}\mathrm{A}: \boldsymbol{p}=\mathbf{0 . 0 3 9} \\
\mathrm{HW}: p=0.334^{*} \\
\tau: p=0.430^{*} \\
\mathrm{~F}: \mathbf{0 . 0 3 1 ^ { * }}\end{array}$ & $\begin{array}{l}\text { AMPA: } \boldsymbol{p}=\mathbf{0 . 0 0 2 ^ { * }} \\
\text { NMDA: } p=0.327^{*} \\
\text { Total: } p=0.054^{*}\end{array}$ & $\begin{array}{l}\mathrm{A}: \boldsymbol{p}<\mathbf{0 . 0 0 1 *} \\
\mathrm{HW}: p=0.348^{*} \\
\tau: p=0.072^{*} \\
\mathrm{~F}: \boldsymbol{p}=\mathbf{0 . 0 0 2 ^ { * }} \\
\mathrm{CT}: p=0.088^{*}\end{array}$ & - & - \\
\hline$t$ test (per animal) & $\begin{array}{l}\tau: p=0.030^{*} \\
\text { PPR: } p=0.003^{*}\end{array}$ & $\begin{array}{l}\mathrm{A}: p=0.093 \\
\mathrm{HW}: p=0.268^{*} \\
\tau: p=0.392 \\
\mathrm{~F}: 0.131^{*}\end{array}$ & $\begin{array}{l}\text { AMPA: } \boldsymbol{p}=\mathbf{0 . 0 3 2} \\
\text { NMDA: } p=0.246^{*} \\
\text { Total: } p=0.072^{*}\end{array}$ & $\begin{array}{l}\mathrm{A}: \boldsymbol{p}=\mathbf{0 . 0 1 0} \\
\mathrm{HW}: p=0.204 \\
\tau: p=0.155 \\
\mathrm{~F}: \boldsymbol{p}=\mathbf{0 . 0 3 2} \\
\mathrm{CT}: \boldsymbol{p}=\mathbf{0 . 0 4 7}\end{array}$ & - & - \\
\hline Two-way repeated-measures ANOVA (per neuron) & $\begin{array}{l}\mathrm{T}: \boldsymbol{p}<\mathbf{0 . 0 0 1} \\
\mathrm{I}-0: \boldsymbol{p}<\mathbf{0 . 0 0 1} \\
\mathrm{T} \times \mathrm{I}-0: \boldsymbol{p}<\mathbf{0 . 0 0 1}\end{array}$ & - & - & - & $\begin{array}{l}\mathrm{T}: \boldsymbol{p}=\mathbf{0 . 0 0 2} \\
\mathrm{Cl}: \boldsymbol{p}<\mathbf{0 . 0 0 1} \\
\mathrm{T} \times \mathrm{Cl}: \boldsymbol{p}<0.001\end{array}$ & $\begin{array}{l}\mathrm{T}: \boldsymbol{p}<\mathbf{0 . 0 0 1} \\
\mathrm{Cl}: \boldsymbol{p}<\mathbf{0 . 0 0 1} \\
\mathrm{T} \times \mathrm{Cl}: p=0.105\end{array}$ \\
\hline Two-way repeated-measures ANOVA (per animal) & $\begin{array}{l}\mathrm{T}: p=0.002 \\
\mathrm{I}-0: \boldsymbol{p}<\mathbf{0 . 0 0 1} \\
\mathrm{T} \times \mathrm{I}-0: \boldsymbol{p}<\mathbf{0 . 0 0 1}\end{array}$ & - & - & - & $\begin{array}{l}\mathrm{T}: \boldsymbol{p}=\mathbf{0 . 0 1 0} \\
\mathrm{Cl}: \boldsymbol{p}<\mathbf{0 . 0 0 1} \\
\mathrm{T} \times \mathrm{Cl}: \boldsymbol{p}=\mathbf{0 . 0 0 1}\end{array}$ & $\begin{array}{l}\mathrm{T}: \boldsymbol{p}=\mathbf{0 . 0 1 6} \\
\mathrm{Cl}: \boldsymbol{p}=\mathbf{0 . 1 3 1} \\
\mathrm{T} \times \mathrm{Cl}: p=0.965\end{array}$ \\
\hline LMM & $\begin{array}{l}\tau: \boldsymbol{p}=\mathbf{0 . 0 0 1} \\
\text { PPR: } \boldsymbol{p}=\mathbf{0 . 0 0 7} \\
\mathrm{I}-0: \boldsymbol{p}<\mathbf{0 . 0 0 1} \\
\mathrm{T} \times \mathrm{I}-0: \boldsymbol{p}<\mathbf{0 . 0 0 1}\end{array}$ & $\begin{array}{l}\mathrm{A}: p=0.257 \\
\mathrm{HW}: p=0.611 \\
\tau: p=0.944 \\
\mathrm{~F}: p=0.311\end{array}$ & $\begin{array}{l}\text { AMPA: } \boldsymbol{p}=\mathbf{0 . 0 2 2} \\
\text { NMDA: } p=0.993 \\
\text { Total: } p=0.243\end{array}$ & $\begin{array}{l}\mathrm{A}: \boldsymbol{p}=\mathbf{0 . 0 2 4} \\
\mathrm{HW}: p=0.324 \\
\tau: p=0.867 \\
\mathrm{~F}: p=0.083 \\
\mathrm{CT}: p=0.167\end{array}$ & $\begin{array}{l}\mathrm{T}: \boldsymbol{p}=\mathbf{0 . 0 0 5} \\
\mathrm{Cl}: \boldsymbol{p}<\mathbf{0 . 0 0 1} \\
\mathrm{T} \times \mathrm{Cl}: p=0.325\end{array}$ & $\begin{array}{l}\mathrm{T}: \boldsymbol{p}<\mathbf{0 . 0 0 1} \\
\mathrm{Cl}: \boldsymbol{p}=\mathbf{0 . 0 0 6} \\
\mathrm{T} \times \mathrm{Cl}: p=0.050\end{array}$ \\
\hline
\end{tabular}

${ }^{a}$ We used $t$ test or two-way repeated-measures ANOVA (per neuron and per animal) and LMM. T, Treatment; $C$, current injection; VS, voltage step; $A$, amplitude; HW, half-width; $F$, frequency; $C T$, charge transfer; $E$ L, SWD event latency; $C D$, cumulative duration of SWD events; $\mathrm{ED}$, SWD cumulative event duration; \% TAP, the percentage of predrug tonic action potential firing; \% BAP, the percentage of predrug burst action potential firing; \% GR, the percentage of GBL response. *Mann-Whitney U test.

Bold indicates statistically significant $p$ values.

the presence of $50 \mu \mathrm{M} \mathrm{D}-\mathrm{APV}$ and $5 \mu \mathrm{M}$ NBQX. The ratio of the maximum amplitude of the first peak to the maximum amplitude of the second was calculated and compared. The time course of eIPCS decay usually was described using a single exponential function. In some cells, decay of eIPSCs was better described using a double exponential function, in which case we used weighted averages for our analyses. In each group, we recorded from pups from at least three different litters.

T-current properties. T-channel activation was measured by stepping the membrane potential from an initial holding potential $\left(\mathrm{V}_{\mathrm{h}}\right)$ of -90 $\mathrm{mV}$ to test potentials $\left(\mathrm{V}_{\mathrm{t}}\right)$ from -80 to $5 \mathrm{mV}$ in $5 \mathrm{mV}$ increments over a period of $320 \mathrm{~ms}$. Current-voltage (I-V) curves were generated, and peak current amplitudes and inactivation properties of current waveforms were established and compared between sham and GA groups. We calculated current densities by measuring average peak current divided by the capacitance of the neuron. Steady-state inactivation curves were generated by using a standard double-pulse protocol with 3.6-s-long prepulses to variable voltages (from -110 to $-50 \mathrm{mV}$ in $5 \mathrm{mV}$ increments) and test potentials to $-50 \mathrm{mV}$. The voltage dependencies of activation and steady-state inactivation were described with single Boltzmann distributions of the following forms:

$$
\begin{aligned}
& \text { Activation: } \mathrm{G}(\mathrm{V})=\mathrm{G}_{\max } /\left(1+\exp \left[-\left(\mathrm{V}-\mathrm{V}_{50}\right) / k\right]\right) \\
& \text { Inactivation: } \mathrm{I}(\mathrm{V})=\mathrm{I}_{\max } /\left(1+\exp \left[\left(\mathrm{V}-\mathrm{V}_{50}\right) / k\right]\right)
\end{aligned}
$$

In these forms, $I_{\max }$ is the maximal amplitude of current, $G_{\max }$ is the maximal conductance (calculated by dividing current amplitude by estimated reversal potential), $\mathrm{V}_{50}$ is the voltage at which half of the current is activated or inactivated, and $k$ represents the voltage dependence (slope) of the distribution.

The time course of macroscopic current inactivation was described using either a single exponential function or double exponential function, in which case we used weighted averages $\left(\tau_{\mathrm{w}}\right)$ for our analyses using the following form:

$$
\tau_{\mathrm{w}}=[(\tau 1 * \mathrm{~A} 1)+(\tau 2 * \mathrm{~A} 2)] /(\mathrm{A} 1+\mathrm{A} 2)
$$

In this form, $\tau 1$ and $\tau 2$ represent inactivation time constants, and $\mathrm{A} 1$ and A2 are their corresponding amplitudes.

Recordings from intact brain slices offer great advantages for studying neurons in an intact setting in vitro. However, the presence of extensive neuronal processes compromises voltage control in whole-cell recordings from slices so that all biophysical measurements must be interpreted with caution. Accordingly, we paid close attention to the signs of good voltage control. Specifically, there was no extensive delay in the onset of current; also, the onset and offset kinetics depended on voltage, not on the amplitude of current. In whole-cell experiments, because intact nRT neurons have long processes, rapid components of recorded currents, such as tail currents, are unlikely to reflect the true amplitude and time course of calcium current behavior. All of our measurements of amplitudes from holding, peak, and steady-state currents were made at time points sufficient to ensure reasonably well-clamped current conditions.

EEG recordings. EEG recordings were obtained from the somatosensory cortex with bilateral stainless steel electrodes accompanied by an operational amplifier (Texas Instruments, TL2274x) in both GA and sham animals. Reference electrodes were placed within the cerebellum (Zaman et al., 2011). The following coordinates were used to place bilateral somatosensory cortex electrodes: from bregma $-2.2 \mathrm{~mm}$ rostrocaudal, $\pm 5.5 \mathrm{~mm}$ mediolateral, $1.5 \mathrm{~mm}$ dorsoventral.

Operational amplifiers were implanted surgically using Iso anesthesia as soon as pups were weaned, and EEG recordings coupled with video recordings were acquired in rats from P19 to P25. Recordings were obtained using tethered wires coupled to a freely moving commutator. EEG signals were acquired using a Grass instruments signal processor; EEG video and signal were analyzed using Harmonie Stellate software.

Induced GBL seizure-like activity. Gamma butyrolactone (GBL; SigmaAldrich), a photosensitive compound, was kept in dark storage until used in the experiments when it was dissolved in sterile saline in stock solutions of $50 \mathrm{mg} / \mathrm{ml}$ for injections of $70 \mathrm{mg} / \mathrm{kg}$. All injections were given intraperitoneally in a sterile fashion. Animals were then monitored for actions resembling absence seizures, such as behavioral arrest with open eyes and vibrissal twitching (Snead, 1988). The EEG recordings showing characteristic spike and wave discharges (SWDs) were analyzed by three independent examiners in a blinded fashion as to whether rats were exposed to GAs or sham anesthesia, and a consensus was reached for summary data. SWDs with voltage amplitudes of at least twice the background EEG and a minimum duration of $0.7 \mathrm{~s}$ were considered to be separate events if they were separated by $>1 \mathrm{~s}$ (Zaman et al., 2011). We did not attempt to analyze baseline EEG activity in either GA-treated or sham-treated rats in the absence of GBL. 


\begin{tabular}{|c|c|c|c|c|c|c|c|}
\hline$\overline{\mathrm{AP} / \mathrm{LTCS}}$ & Input resistance & Current density activation & $\mathrm{V}_{50}$ activation & Current density inactivation & $V_{50}$ inactivation & EEG & T-channel antagonism \\
\hline - & - & - & $p<0.001^{*}$ & - & $p=0.018$ & - & - \\
\hline
\end{tabular}

\begin{tabular}{|c|c|c|c|c|c|c|c|}
\hline - & - & - & $p=0.003^{*}$ & - & $p=0.002$ & $\begin{array}{l}\mathrm{EL}: p=0.443 \\
\mathrm{CD}: \boldsymbol{p}=\mathbf{0 . 0 0 5}\end{array}$ & $\begin{array}{l}\% \text { TAP: } \boldsymbol{p}=\mathbf{0 . 0 0 8} \\
\% \text { BAP: } \boldsymbol{p}<\mathbf{0 . 0 0 1}\end{array}$ \\
\hline & & & & & & & $\% G R: p=0.003$ \\
\hline $\mathrm{T}: \boldsymbol{p}=\mathbf{0 . 0 0 2}$ & $\mathrm{T}: p=0.599$ & $\mathrm{~T}: \boldsymbol{p}=\mathbf{0 . 0 0 4}$ & - & $\mathrm{T}: \boldsymbol{p}<\mathbf{0 . 0 0 1}$ & - & - & - \\
\hline $\mathrm{Cl}: p<0.001$ & $\mathrm{Cl}: p=0.514$ & VS: $p<0.001$ & & VS: $p<0.001$ & & & \\
\hline $\mathrm{T} \times \mathrm{Cl}: p=0.116$ & $\mathrm{~T} \times \mathrm{Cl}: p=0.750$ & $T \times V S: p<0.001$ & & $T \times V S: p<0.001$ & & & \\
\hline $\mathrm{T}: \boldsymbol{p}=\mathbf{0 . 0 1 2}$ & $\mathrm{T}: p=0.613$ & $\mathrm{~T}: \boldsymbol{p}=\mathbf{0 . 0 3 7}$ & - & $\mathrm{T}: \boldsymbol{p}=\mathbf{0 . 0 1 2}$ & - & - & - \\
\hline $\mathrm{Cl}: p<0.001$ & $\mathrm{Cl}: p=0.871$ & $\mathrm{Cl}: p<0.001$ & & VS: $p<0.001$ & & & \\
\hline $\mathrm{T} \times \mathrm{Cl}: p=0.272$ & $\mathrm{~T} \times \mathrm{Cl}: p=0.705$ & $\mathrm{~T} \times \mathrm{Cl}: p=0.095$ & & $T \times V S: p<0.001$ & & & \\
\hline $\mathrm{T}: \boldsymbol{p}=\mathbf{0 . 0 0 3}$ & $\mathrm{T}: p=0.603$ & $\mathrm{~T}: \boldsymbol{p}=\mathbf{0 . 0 0 4}$ & $p=0.004$ & $\mathrm{~T}: p<0.001$ & $p=0.043$ & (ED) & $\%$ TAP: $\boldsymbol{p}=\mathbf{0 . 0 1 6}$ \\
\hline $\mathrm{Cl}: p=0.001$ & $\mathrm{Cl}: p=0.427$ & VS: $p<0.001$ & & VS: $\boldsymbol{p}<\mathbf{0 . 0 0 1}$ & & $\mathrm{T}: \boldsymbol{p}=\mathbf{0 . 0 2 6}$ & $\%$ BAP: $\boldsymbol{p}<\mathbf{0 . 0 0 1}$ \\
\hline $\mathrm{T} \times \mathrm{Cl}: p=0.367$ & $\mathrm{~T} \times \mathrm{Cl}: p=0.050$ & $T \times V S: p=0.002$ & & $\mathrm{~T} \times \mathrm{VS}: \boldsymbol{p}=\mathbf{0 . 0 0 1}$ & & Time: $\boldsymbol{p}<\mathbf{0 . 0 0 1}$ & \\
\hline & & & & & & $\mathrm{T} \times$ Time: $p=0.063$ & $\%$ GR:p $\boldsymbol{p}=\mathbf{0 . 0 0 6}$ \\
\hline
\end{tabular}

TTA-P2 (3,5-dichloro- $N$-[1-(2,2-dimethyl-tetrahydro-pyran-4-ylmethyl)4-fluoro-piperidin-4-ylmethyl]-benzamide) kindly was provided by Dr. V.N. Uebele. For in vivo studies, TTA-P2 was dissolved in DMSO at a concentration of $4 \mathrm{mg} / \mathrm{ml}$ and then diluted to $2 \mathrm{mg} / \mathrm{ml}$ using PBS. TTA-P2 pretreatment at a dose of $5 \mathrm{mg} / \mathrm{kg}$ (i.p.) was given at an average of $2.5 \mathrm{~h}$ before the first GBL treatment. A second injection of GBL in the same rats was administered at a minimum of $4 \mathrm{~h}$ after the first GBL treatment, and the resulting EEG responses were analyzed and compared with those after the first injection of GBL. For electrophysiology experiments in vitro, TTA-P2 was dissolved at a concentration of $300 \mathrm{~mm}$ and then serially diluted in the appropriate external solution.

Data analysis. In every in vitro experiment, we attempted to obtain as many neurons as possible from each animal to minimize the number of animals used. Statistical analyses for all electrophysiology studies were clustered according to animal. For pairwise and repeated measures experiments, we applied linear mixed models (LMMs) to account for intracluster correlation effects and to avoid reducing the data to means per animal (Galbraith et al., 2010). Statistical analysis was also performed using one-way and two-way ANOVA, Mann-Whitney rank sum test, as well as Student $t$ test and paired $t$ test where appropriate. Where applicable, Student-Newman-Keuls (SNK) or Bonferroni tests for post hoc comparisons were also used. Significance was accepted with $p$ values $<0.05$. All $p$ values are reported in Table 1, thus providing a comprehensive overview and comparison between results originating from different analysis (per neuron, per animal, and LMM). Statistical and graphical analysis was performed using GraphPad Prism 5.01 software (GraphPad Software), Origin 7.0 (OriginLab). LMM statistical analyses for pairwise and repeated measures factors were conducted using PASW Statistics 18 (SPSS).

\section{Results}

\section{Plasticity of inhibitory synaptic transmission in the rat} thalamus after single exposure to GA

Stimulation of fibers in close proximity to the internal capsule ( $\sim 200 \mu \mathrm{m}$ from recorded nRT neurons) evokes picrotoxinsensitive $\mathrm{GABA}_{\mathrm{A}}$-mediated eIPSCs in $\mathrm{nRT}$ neurons as we previously described in detail (Joksovic et al., 2009). Figure 1 (A, left) shows an average of 20 traces of eIPSCs in the population of nRT neurons from the sham group (black trace) and an average of 22 traces of eIPSCs in the population of nRT neurons from the group exposed to GA (gray trace). eIPSCs from GA-exposed animals showed an $\sim 50 \%$ decrease in peak amplitudes (average $48 \pm 10 \%, p<0.001, t$ test) compared with those from the sham group. Normalized traces depicted in Figure $1 A$ (right) and in Figure $1 B$ (bar graphs) show that decay $\tau$ for eIPSCs in GAtreated pups (gray squares, $86 \pm 5 \mathrm{~ms}$ ) was significantly decreased compared with that from sham-treated animals (black squares, $115 \pm 13 \mathrm{~ms}, p=0.001, \mathrm{LMM})$. We also found that stimulus input-output (I-O) curves after exposure to GA (black squares) were significantly ( $p<0.001$, LMM) reduced to $\sim 40 \%-$ $60 \%$ of curves from the sham group $(\bigcirc)$ across most stimulus intensities (Fig. 1C).

We next studied mechanisms of synaptic plasticity using paired-pulse analysis. In nRT neurons, stimulation with a pairedpulse stimulus interval of $1 \mathrm{~s}$ usually results in depression of the second (test) IPSC compared with the first (conditioning) IPSC (Joksovic et al., 2009). This depression of PPR of test IPSCs relative to conditioning IPSCs has been proposed to be due to depletion of a fraction of readily available synaptic vesicles by the conditioning pulse (Zucker and Regehr, 2002). Representative traces from paired-pulse experiments in nRT neurons from the sham (black trace) and GA-treated rats (gray trace) are depicted in Fig. $1 D$. In summary, Figure $1 E$ (bar graphs) shows that the average PPR was significantly decreased in the GA group (gray squares, $0.77 \pm 0.03$ ) compared with that from the sham group (black squares, $0.90 \pm 0.03, p<0.01, \mathrm{LMM}$ ), strongly suggesting involvement of presynaptic mechanisms of synaptic plasticity.

Subsequently, we recorded mIPSCs to discern independently any possible presynaptic and postsynaptic effects of GAs on inhibitory synapses. Typically, in studies of AP-independent miniature synaptic events, any changes in frequency reflect presynaptic mechanisms, whereas alterations of event amplitudes and/or kinetics usually reflect postsynaptic mechanisms. Original traces of mIPSCs from representative nRT neurons in sham (top black trace) and GA (bottom red trace) groups are depicted in 


\section{eIPSCs}

A
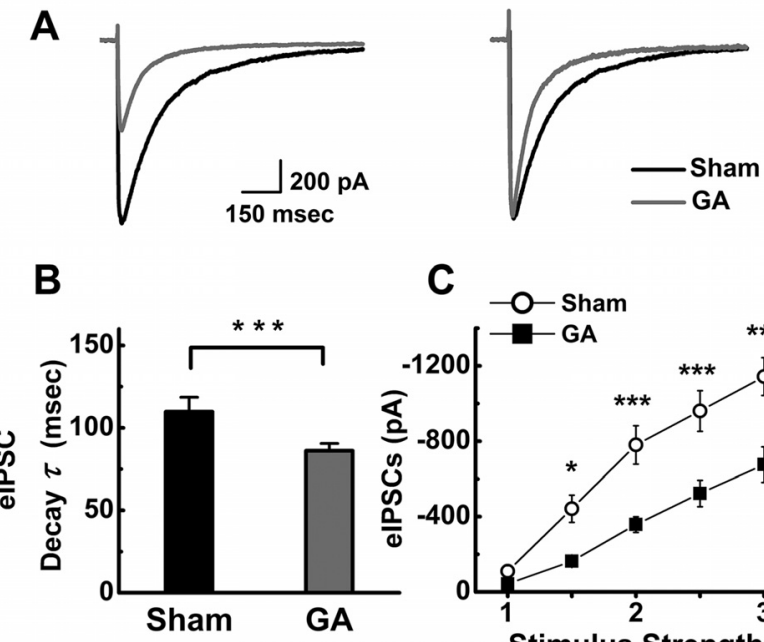

D

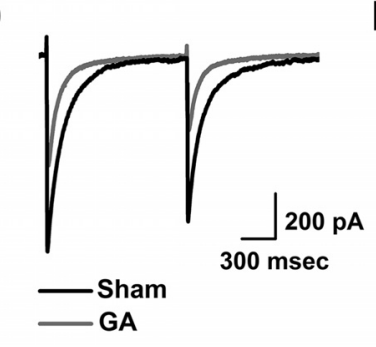

C

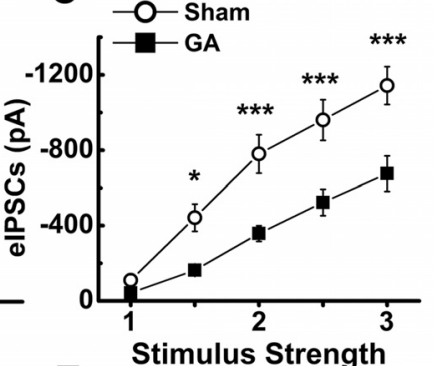

E

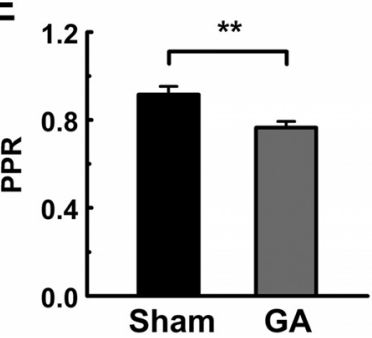

Figure 1. Alterations in elPSCS of nRT neurons mediated by GA exposure. $A$, Left, Averaged traces from nRT neurons from the sham group (black trace) and the GA-exposed group (gray trace). Right, Same traces of elPSCs as in $\boldsymbol{A}$ that are scaled for easier comparison. There is faster decay of current in the GA group. $\boldsymbol{B}$, Decay time constants are decreased in the GA (13 rats, 45 neurons) versus the sham ( 23 rats, 63 neurons) group ${ }^{* * *} p<0.001$ by LMM). $C$, The averaged data of I-0 curves show decreased synaptic strength of elPSCs in the GA group ( $\mathbf{\square}, 12$ rats, 41 neurons) versus the sham group $\left(\bigcirc, 15\right.$ rats, 52 neurons). ${ }^{*} p<0.05$ (SNK post hoc test). ${ }^{* * *} p<0.001$ (SNK post hoc test). We first determined threshold stimulus (denoted as 1 ) in each experiment; then we used progressively stronger stimuli 1.5-, 2-, 2.5-, and 3-fold higher than the threshold stimulus. $\boldsymbol{D}$, Averaged traces of paired-pulse stimulus protocol separated by $1 \mathrm{~s}$ show elPSCs in sham group (black trace) and GA group (gray trace). $\boldsymbol{E}$, Bar graph shows that, in $G A$-treated animals (13 rats, 37 neurons), the average PPR ratio is significantly decreased compared with that in sham-treated animals (19 rats, 56 neurons). ${ }^{* *} p<0.01$ (LMM). B, C, E, All symbols represent mean values grouped by animal \pm SEM.

Figure $2 A$. Cumulative probabilities of mIPSCs amplitudes, decay times estimated by measuring half-widths, and frequency measured by IEIs from all recordings in the sham group (black lines) and the GA group (red lines) are depicted in Figure $2 B-E$. In contrast to the effects on eIPSCs, we found a small but nonsignificant difference when we compared the average amplitudes (Fig. 2B,C) of mIPSCs between sham $(35.8 \pm 4.0 \mathrm{pA})$ and GA groups $(29.1 \pm 2.8 \mathrm{pA})(p>0.05, \mathrm{LMM})$. We found similar values for half-width (Fig. $2 D$ ) and frequency (Fig. 2E) of spontaneous mIPSCs between cells from the animals in sham group and the GA groups ( $p>0.05, \mathrm{LMM})$. We also found a minimal difference in estimated average decay $\tau$ values of mIPSCs between the GA $(73 \pm 8 \mathrm{~ms})$ and sham group $(76 \pm 10 \mathrm{~ms})$ (data not shown).

Plasticity of excitatory synaptic transmission in the rat thalamus after single exposure to GA

Alterations in glutamate receptor function and/or glutamate release may lead to alterations in neuronal excitability within the nRT, which, in turn, leads to altered circuit activity (Beyer et al.,

A mIPSCs

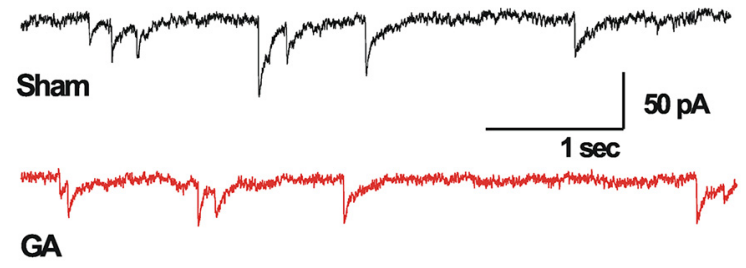

B

D
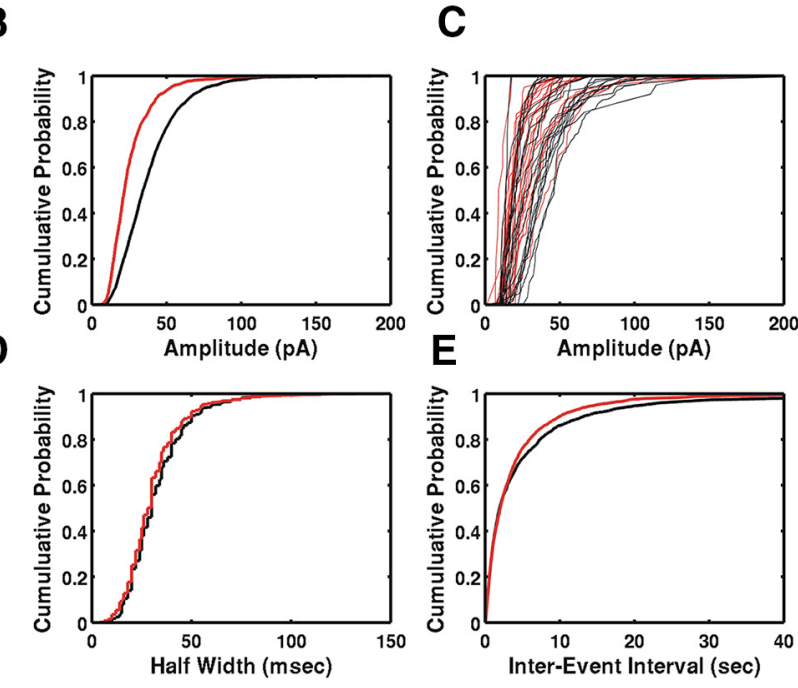

Figure 2. Effects of GA exposure on mIPSCs of nRT neurons. $\boldsymbol{A}$, Sample of original mIPSC traces from sham (black) and GA-treated (red) nRT neurons. $\boldsymbol{B}-\boldsymbol{E}$, Plots describing CDFs of isolated mIPSC events in the sham group (1971 events) and the GA group (1659 events) demonstrate very little change in the amplitude $(\boldsymbol{B}, \boldsymbol{C})$, kinetics $(\boldsymbol{D})$, and frequency $(\boldsymbol{E})$ of events $(p>$ 0.05 , LMM). $\boldsymbol{B}, \boldsymbol{D}, \boldsymbol{E}$, Solid lines indicate averages of all events for sham (black lines) and GA (red lines) groups. $C$, CDFs for the amplitudes of mIPSCs in all nRT neurons used for this analysis in sham (black lines, 21 neurons) and GA (red lines, 21 neurons) groups. Data presented were obtained from $10 \mathrm{GA}$-treated rats and 7 sham-treated rats.

2008; Paz et al., 2011; Lacey et al., 2012). Thus, we used an experimental strategy that characterizes both properties of eEPSCs and mEPSCs to understand any possible GA-mediated changes to the excitatory synapse in terms of an intact circuit. We found that, in most of the nRT neurons, eEPSCs consisted of two components based on different decay $\tau$ s. We first demonstrated that the slower-decaying component of eEPSCs was completely blocked by $50 \mu \mathrm{M} \mathrm{D}-\mathrm{APV}$, an NMDA receptor antagonist, whereas the faster-decaying component of eEPSCs was completely blocked by $5 \mu \mathrm{M}$ NBQX, an AMPA receptor antagonist (Fig. 3A). We also found that selective T-channel blocker TTA-P2 at $10 \mu \mathrm{M}$ concentration did not significantly affect the shape and amplitude of baseline eEPSCs in nRT neurons after $10 \mathrm{~min}$ of incubation in external solution ( $6 \pm 14 \%$ change, $n=3, p>0.05$; Fig. $3 A$, inset). We then challenged nRT neurons with $50 \mu \mathrm{M}$ D-APV and compared the amplitudes of pharmacologically isolated eEPSCs between the nRT neurons in the sham group $(\square)$ and nRT neurons from the GA group ( $\mathbf{\square}$, Fig. $3 B$ ). We found that the maximal amplitude of eEPSCs in the sham group was $648 \pm 90 \mathrm{pA}$, whereas in the GA group, it was $1094 \pm 226 \mathrm{pA}(p>0.05, \mathrm{LMM})$. However, when we compared the amplitudes of D-APVinsensitive components only, we found that GA group (536 \pm 83 pA) was significantly increased compared with the sham group $(295 \pm 71 \mathrm{pA}, p<0.05, \mathrm{LMM})$. In contrast, we found that the amplitudes of D-APV-sensitive components in the GA group 

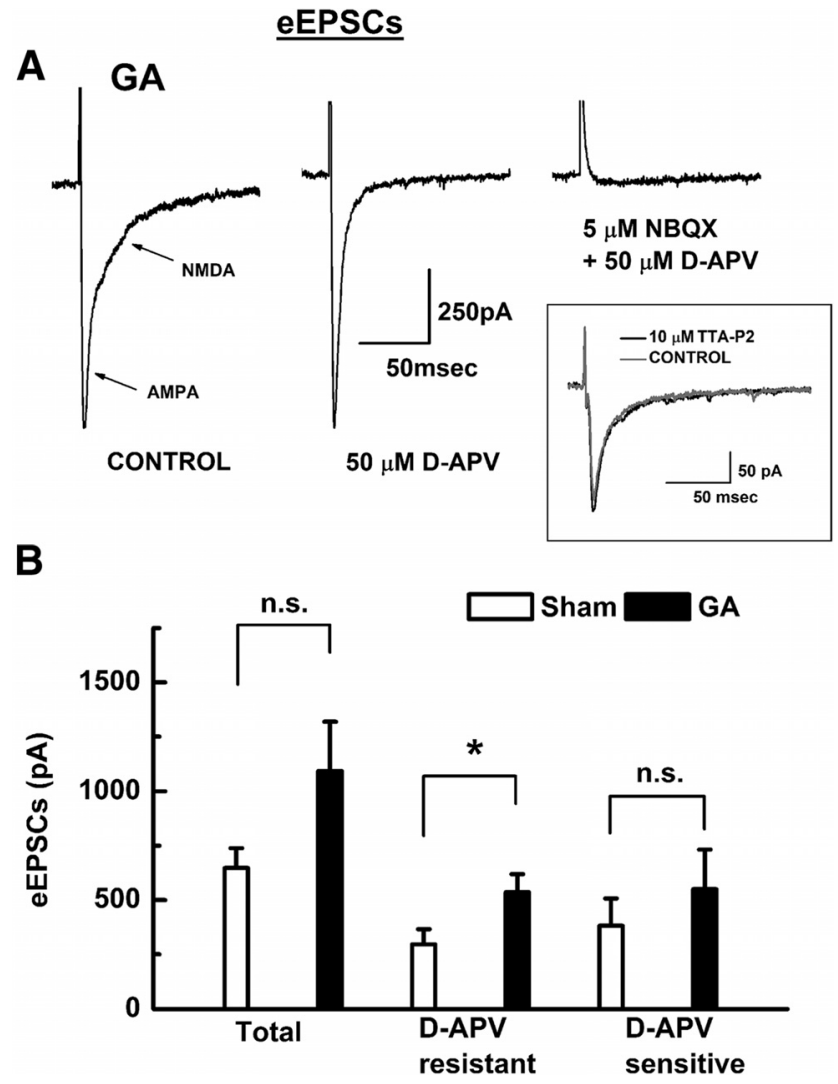

Figure 3. GA exposure increases the AMPA component of $n R T$ neuron eEPSCs. A, Progressive eEPSC current blockade in a representative nRT neuron from the GA-treated group. Bath application of $50 \mu \mathrm{m} \mathrm{D}$-APV blocks the slower component of eEPSCs mediated by NMDA currents and isolates AMPA currents. A subsequent application of $5 \mu \mathrm{M}$ NBQX induced almost complete blockade of the remaining current. Inset, Traces from a representative neuron from the GA group in the control conditions (gray trace) and after exposure to $10 \mu \mathrm{M}$ TTA-P2 for $10 \mathrm{~min}$ (black trace). $\boldsymbol{B}$, Bar graphs of average values show that there is no significant difference (n.s., $p>0.05, \mathrm{LMM})$ in the total eEPSC amplitudes in GA $(\square, 7$ rats, 17 neurons) and sham $(\square, 5$ rats, 17 neurons) groups. However, pharmacological separation of excitatory currents reveals a significant increase in D-APV-resistant (AMPA component) current amplitudes ( ${ }^{*} p<0.05$, LMM), whereas the D-APV-sensitive component of eEPSCs (NMDA component) in nRT neurons is similar in both groups (n.s., $p>0.05$, LMM). Bar graphs represent mean values grouped by animal \pm SEM.

$(550 \pm 182 \mathrm{pA})$ were not significantly different from those in the sham group $(381 \pm 126 \mathrm{pA}, p>0.05, \mathrm{LMM})$. We also found very little difference in PPR of the D-APV-insensitive component of eEPSCs in nRT cells between the sham group $(0.73 \pm 0.06)$ and the GA group ( $0.81 \pm 0.05, p>0.05$, data not shown). Therefore, we concluded that the AMPA component of eEPSCs is increased in rats exposed to GAs, likely by postsynaptic mechanisms, whereas the NMDA component of eEPSCs is spared in GAtreated rats.

We next recorded mEPSCs to independently study potential mechanisms for GA-induced plasticity of excitatory synaptic transmission in these neurons. Figure $4 A$ shows representative original traces from the nRT cells in the sham group (top black trace) and the GA group (bottom red trace). Cumulative probabilities of mEPSC amplitudes, decay times estimated by measuring half-widths, and frequency measured by IEIs from all recordings in the sham group (black lines) and the GA group (red lines) are depicted in Figure $4 B-E$. We found that, on average, the amplitudes of events were significantly increased in the GA group $(14.1 \pm 2.2 \mathrm{pA})$ compared with those in the sham group $(9.5 \pm$ $1.2 \mathrm{pA}, p<0.05$ LMM; Fig. 4B). However, Figure $4 D$ shows that
A
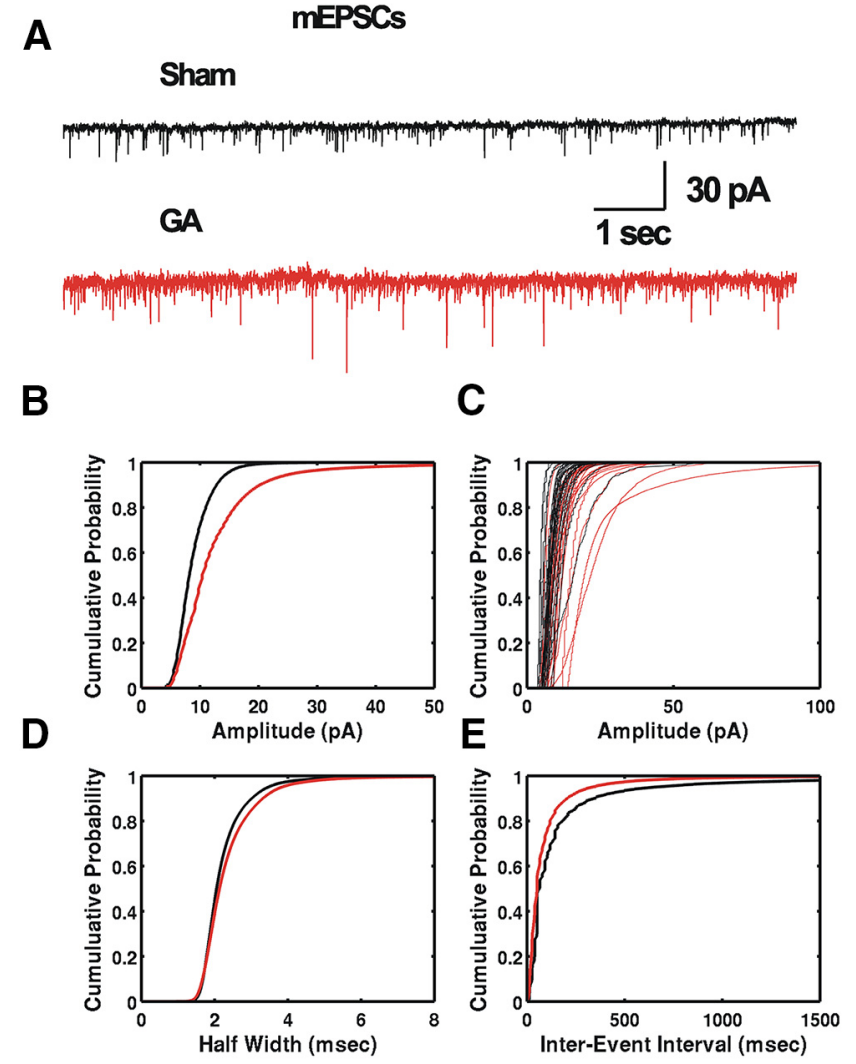

Figure 4. GA exposure alters $n R T$ neuron mEPSC properties. $\boldsymbol{A}$, Sample of original mEPSC traces from sham (black) and GA-treated (red) nRT neurons. $\boldsymbol{B}-\boldsymbol{E}$, Plots describing CDFs of isolated $\mathrm{mEPSC}$ events in the sham group (78,987 events) and the GA group $(154,951$ events) demonstrate a significant $(p<0.05, \mathrm{LMM})$ increase in the amplitude $(\boldsymbol{B}, \boldsymbol{C})$ and no significant change ( $p>0.05, \mathrm{LMM})$ in kinetics $(\boldsymbol{D})$ and frequency $(\boldsymbol{E})$ of events. $\boldsymbol{B}, \boldsymbol{D}, \boldsymbol{E}$, Solid lines indicate averages of all events for the sham (black lines) and GA (red lines) groups. C, CDFs for the amplitudes of mEPSC in all nRT neurons used for this analysis in sham (black lines, 29 neurons) and GA (red lines, 28 neurons) groups. Data presented were obtained from 9 GA-treated animals and 8 sham-treated animals.

the half-widths were similar in the GA group $(3.0 \pm 0.2 \mathrm{~ms})$ and the sham group $(2.8 \pm 1.8 \mathrm{~ms}, p>0.05 \mathrm{LMM})$. Despite the fact that the GA group had higher frequencies of mEPSCs $(9.5 \pm 2.5$ $\mathrm{Hz})$ compared with the sham group $(3.6 \pm 1.5 \mathrm{~Hz})$, the difference was not statistically significant ( $p>0.05$ by LMM; Fig. $4 E$ ). Overall, our data with mEPSCs independently confirmed that the GA-induced increase in AMPA-mediated excitatory synaptic transmission is mostly mediated by postsynaptic mechanisms.

Exposure of rat pups at age P7 to GA leads to lasting increase in intrinsic cellular excitability and increased T-current density in $\mathrm{nRT}$ neurons

We next examined possible alterations in intrinsic excitability of nRT cells in GA-treated rats. For these experiments, we used current-clamp experiments and monitored patterns of spike firing in nRT cells from rats exposed to GA or sham treatment. It is well established that nRT neurons exhibit tonic firing patterns of single APs at depolarized membrane potentials (Steriade et al., 1990). Original traces from representative neurons (Fig. 5A) indicate that, at current injections of 20,70 , and $150 \mathrm{pA}$, a neuron from the GA group (top gray traces) responded with relatively uniform APs at higher firing frequencies than a neuron from the sham group (bottom black traces). Similarly, average graphs from multiple experiments (Fig. 5B) show that, compared with neurons from the sham group $(O)$, neurons from the GA group 

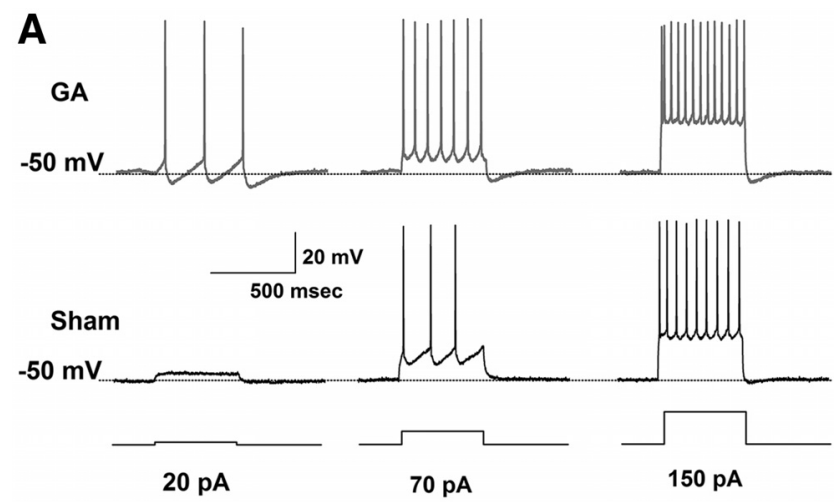

B

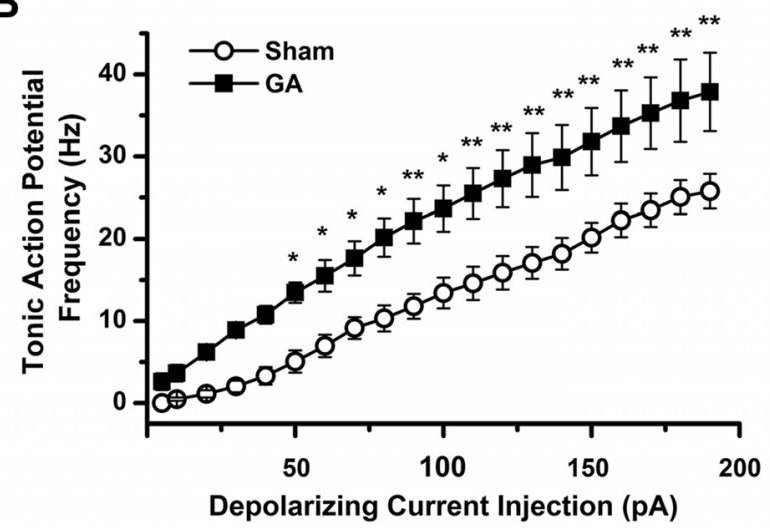

Figure 5. Depolarization-induced tonic firing pattern of $n R T$ neurons is altered in GAexposed rats. $A$, Original traces from representative nRT neurons from GA-treated (top gray traces) and sham-treated (middle black traces) rats show active membrane responses to escalating depolarizing current injections of 20,70, and $150 \mathrm{pA}$ via recording electrode. Bottom traces, Current injection protocols. At all current injections, neurons from GA-treated rats fired more APs compared with nRT neurons from sham-treated rats. At the current injection of $20 \mathrm{pA}$, the sham-treated neuron did not fire at all, whereas the GA-treated neuron fired 3 APs. Dotted lines indicate RMP of $-50 \mathrm{mV}$. $\boldsymbol{B}$, Graph of average values shows that a family of escalating current injections induced more firing APs in the GA-treated group $(\boldsymbol{\square}, 17$ neurons from 6 rats), compared with $n R T$ neurons from the sham-treated group $\left(\bigcirc, 18\right.$ neurons from 8 rats). ${ }^{*} p<$ 0.05 (SNK post hoc test). ${ }^{* *} p<0.01$ (SNK post hoc test). B, Symbols indicate mean values grouped by animal \pm SEM.

responded with a higher average firing frequency across all current pulses (overall significance, $p<0.01, \mathrm{LMM}$ ).

Thalamic neurons exhibit a characteristic oscillatory burstfiring mode after periods of membrane hyperpolarization that may occur during inhibitory synaptic potentials in vivo (Steriade et al., 1990). Thus, we asked whether the rebound firing frequencies in GA-treated versus sham groups were different if the cells had been hyperpolarized by progressively larger current injections. We injected a series of hyperpolarizing currents of the same duration, generating a hyperpolarized resting membrane potential (RMP) (Fig. 6A, top traces), to assess membrane input resistance $\left(\mathrm{R}_{\text {in }}\right)$ and to quantify rebound burst firing. Figure $6 \mathrm{~A}$ shows typical membrane responses to the series hyperpolarizing current injections in representative nRT neurons from the sham-treated group (middle traces) and GA-treated group (bottom trace). After injection of a hyperpolarizing current of sufficient amplitude via recording electrode to remove inactivation of T-current, the same neurons exhibited rebound low-threshold-calcium spikes (LTCSs) and burstfiring mode (Fig. 6A, gray arrows). The burst-firing mode was more readily evoked in the neurons from the GA group than in neurons from the sham group.

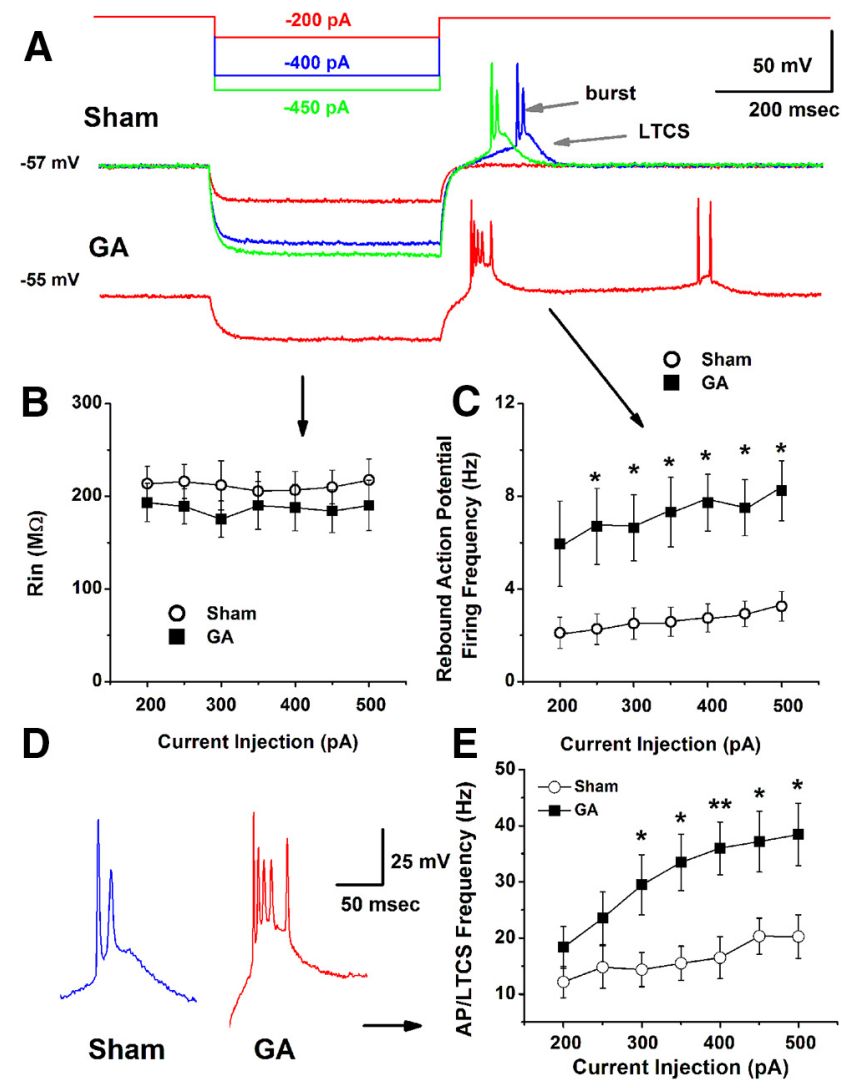

Figure 6. Hyperpolarization-induced burst spike firing pattern of nRT neurons is altered in GA-exposed rats. $\boldsymbol{A}$, Top, Illustration of the current injection protocol used in our experiments, in which neurons are hyperpolarized with a series of $-200,-400$, and $-450 \mathrm{pA}$ current injections via the recording electrode. Middle traces, Passive membrane response of an $n R T$ neuron from the sham group followed by rebound LTCSs and burst firing of APs resulting from current injections of $-200 \mathrm{pA}$ (red trace), $-400 \mathrm{pA}$ (blue trace), and $-450 \mathrm{pA}$ (green trace). Bottom red trace, Passive membrane responses and rebound burst-firing pattern of an $n R T$ neuron from the GA group treated with a current injection of $-200 \mathrm{pA}$. The current injection of $-200 \mathrm{pA}$ evoked burst-firing mode in an $\mathrm{nRT}$ neuron from a GA-treated rat (bottom red trace), whereas the same current injection failed to evoke rebound burst firing in an $\mathrm{nRT}$ neuron from a shamtreated rat (middle red trace). Twofold stronger current injections ( -400 and $-450 \mathrm{pA}$ ) were needed to evoked rebound burst firing in this nRT neuron from the sham-treated rat (blue and green traces on middle panel, respectively). $\boldsymbol{B}$, There was very little difference between sham and GA groups in $\mathrm{R}_{\text {in }}$ in the nRT neurons subjected to hyperpolarized current injections. $\boldsymbol{C}$, Average data points on this graph indicate that the rebound firing frequency, measured during the 1.2-s-long period following the preceding hyperpolarizing prepulses, was approximately threefold increased in the GA-treated group $(\square)$ compared with the sham group (O). D, Original traces show LTCS and burst of AP evoked by current injections of $-400 \mathrm{pA}$ in an $\mathrm{nRT}$ neuron from the sham group (blue trace), and $-200 \mathrm{pA}$ in an nRT neuron from the GA group (red trace), respectively. The traces are from the same nRT neurons presented in $\boldsymbol{A}$. $\boldsymbol{E}$, Graph bars represent the average frequency of APs per evoked LTCSs with escalating current injections in the sham (O) and GA-treated ( $\square$ ) groups. Data points indicate means grouped by animal \pm SEM. ${ }^{*} p<$ 0.05 (SNK post hoc test). ${ }^{* *} p<0.01$ (SNK post hoc test). Data were obtained from $16 \mathrm{GA}$-treated rats ( 25 neurons) and 10 sham-treated rats ( 24 neurons).

We found that the average $R_{\text {in }}$ of these neurons was not very different between the two groups over the range of tested current injections (Fig. 6B). Similarly, there was very little difference between the two groups in RMPs (GA $-54 \pm 3 \mathrm{mV}$; sham $-56 \pm 1$ $\mathrm{mV} ; p>0.05$; data not shown). In contrast, Figure $6 \mathrm{C}$ shows that the same amplitudes of hyperpolarizing current injections induced significantly (approximately threefold, overall $p<0.001$, LMM) higher AP firing frequency in the GA-treated group ( $\square$ ) than in the sham-treated group $(O)$. We also compared the frequency of APs during LTCSs in these neurons and found that it was increased 2.5 -fold over the range of the same current injec- 
A
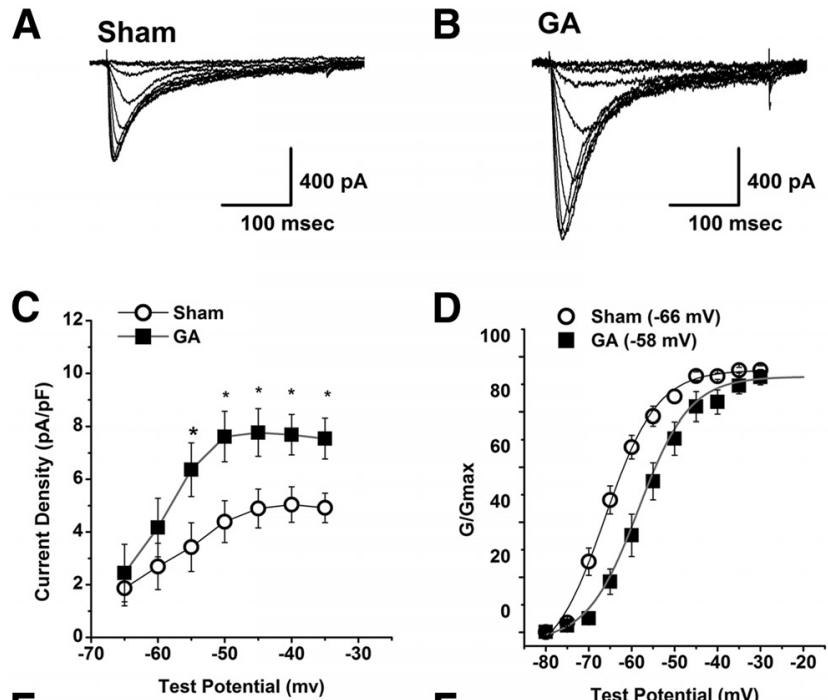

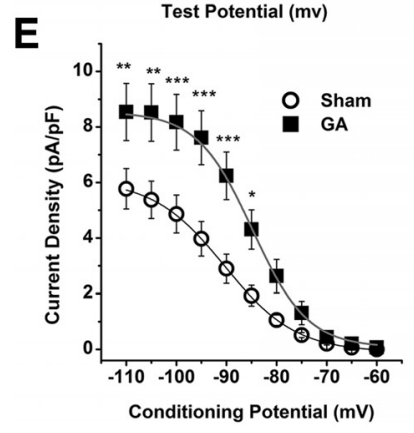

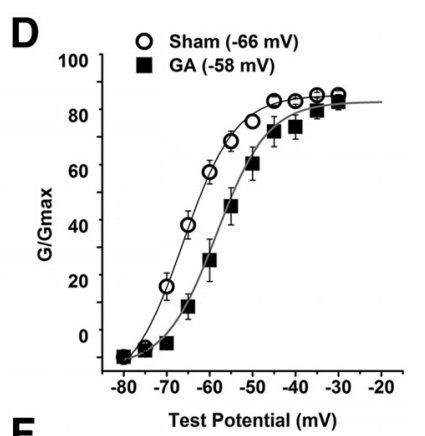

$\mathbf{F}$

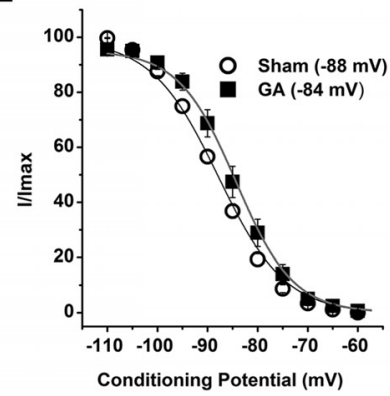

Figure 7. T-current properties of $n R T$ neurons are altered by exposure to GA. $A, B$, Representative families of original T-current traces from both sham $(\boldsymbol{A})$ and GA $(\boldsymbol{B}) \mathrm{nRT}$ neurons in the range of $V_{t}$ from -80 to $-35 \mathrm{mV}$ from $V_{h}$ of $-90 \mathrm{mV}$. Bars represent calibration. $C$, T-current density, as calculated from the voltage dependence of activation, is increased approximately twofold across a broad range of test potentials in the GA-treated group (14 rats, 40 neurons) compared with the sham group (12 rats, 49 neurons). ${ }^{*} p<0.05$ (SNK post hoc test). $\boldsymbol{D}, \mathrm{T} \mathrm{V}_{50}$ for the voltage dependence of activation (noted in parentheses) for the GA ( $\square, 14$ rats, 43 neurons) group demonstrated a significant depolarizing shift of $8 \mathrm{mV}(p<0.01$, LMM) compared with that in the sham $(O, 18$ rats, 55 neurons) group. $\boldsymbol{E}$, T-current density, as calculated from the voltage dependence of inactivation, is increased approximately twofold in the GA group (13 rats, 31 neurons) compared with the sham group ( 9 rats, 22 neurons) across a broad range of conditioning potentials. ${ }^{*} p<0.05$ (SNK post hoc test). ${ }^{* *} p<0.01$ (SNK post hoc test). ${ }^{* * *} p<0.001$ (SNK post hoc test). $\boldsymbol{F}$, The $V_{50}$ of the voltage dependence of inactivation of the GA group (12 rats, 30 neurons) also demonstrated a small but significant depolarizing shift (as noted in parentheses) compared with that in the sham group (14 rats, 45 neurons, $p<0.05$ by LMM). $\boldsymbol{C}-\boldsymbol{F}$, Symbols represent mean values grouped by animal \pm SEM.

tion (overall $p<0.01, \mathrm{LMM}$ ) in the GA group compared with the sham group (Fig. 6D,E). Hence, increased excitability of nRT neurons in GA-treated animals cannot be attributed to alteration of passive membrane properties.

Because T-channels are crucially involved in burst firing of thalamic neurons, we tested the hypothesis that alterations in $\mathrm{T}$-current density and/or biophysical properties could have contributed to increased intrinsic excitability of nRT neurons in the GA group. T-current waveforms in representative nRT neurons from the sham and GA groups are depicted in Figure $7 A$ and Figure $7 B$, respectively. Using I-V relationships, we found that, on average, peak T-current densities were up to twofold increased in the GA group $(\square)$ compared with the sham group $(\bigcirc)$ over the range of test potentials (Fig. $7 C$; overall $p<0.01$, LMM). Figure $7 D$ shows that $\mathrm{V}_{50}$ for the voltage dependence of activation in the GA group was significantly more depolarized by $\sim 8 \mathrm{mV}(\boldsymbol{\square}$, $-58 \pm 2 \mathrm{mV})$ compared with that in the sham group $(\bigcirc,-66 \pm$
$1 \mathrm{mV}, p<0.01, \mathrm{LMM})$. The time constant of T-current inactivation in these neurons was assessed by fitting the decaying portions of the current waveforms at the peak potentials of the I-V relationships (typically $\mathrm{V}_{\mathrm{t}}-50 \mathrm{mV}$ ) with a single or double exponential function. We found that these values were not statistically different ( $p>0.05, t$ test) between GA (62 \pm 4 ms, 13 rats, 36 neurons) and sham groups ( $59 \pm 3 \mathrm{~ms}, 16$ rats, 55 neurons). We next used an independent test to compare current densities in GA and sham groups when T-currents are evoked using steady-state inactivation protocols. Average data points presented in Figure $7 E$ demonstrate that current densities were increased approximately twofold in the GA group ( $\square$ ) compared with those in the sham group $(\bigcirc)$ over the range of membrane potentials (overall $p<0.001, \mathrm{LMM}$ ). We also calculated the voltage dependence of inactivation using Boltzmann fits. Similar to the voltage dependence of activation, Figure $7 F$ shows that $\mathrm{V}_{50}$ for the voltage dependence of inactivation in the GA group also demonstrated a small but significant depolarizing shift of $\sim 4 \mathrm{mV}(\boldsymbol{\square},-84 \pm 1 \mathrm{mV})$ compared with the shams $(O,-88 \pm 2 \mathrm{mV}, p<0.05$, LMM). Therefore, changes in biophysical properties of T-currents may also contribute to hyperexcitability of nRT neurons in the GA-treated group.

\section{Adolescent rats exposed to GAs at age P7 display hyperexcitability of intact TC networks}

Characteristic oscillatory activity of mutually connected nRT, TC, and Ctx neurons may underlie many physiological and pathological processes, including absence seizures; and the roles of GABA $_{\mathrm{A}}$ (Beenhakker and Huguenard, 2009), AMPA (Beyer et al., 2008; Lacey et al., 2012), and T-channels (Khosravani and Zamponi, 2006) in this disorder are well established. Typical absence seizures are characterized by a brief loss of consciousness and the appearance of 3-5 Hz SWDs in the EEG that result from paroxysmal and synchronized firing in thalamic and Ctx networks. Our findings that the amplitudes of eIPSCs in nRT neurons from GA-treated rats are diminished are similar to those from a genetic rat model of absence seizures (Bessaïh et al., 2006). Hence, we hypothesized that hyperexcitability of $\mathrm{nRT}$ neurons resulting from plasticity of AMPA, $\mathrm{GABA}_{\mathrm{A}}$ receptors, and T-channels in concert could increase the propensity for absence seizures in GAtreated rats. To address this issue, we used in vivo EEG recordings in freely moving animals in a commonly used rodent model of absence seizures that uses systemic administration of $\mathrm{GABA}_{\mathrm{B}}$ agonists, such as GBL, a prodrug of $\gamma$-hydroxybutyrate (Snead, 1988). Figure 8 shows representative traces of original EEG recordings from a rat that received GA (Fig. $8 A$ ) and from a rat that received sham anesthesia (Fig. $8 B$ ). The top trace in each panel (line a) shows baseline awake EEG activity characterized by a mixture of low-frequency and high-frequency waveforms. In contrast, Figure $8 A, B$ (middle traces, lines b-d) and the traces on expanded time scale (panels 1 and 2) show periods of characteristic high amplitude 3-5 Hz activity consistent with GBL-induced SWDs. Figure $8 A, B$ (bottom lines, line e) shows final SWD events and return of EEG to the awake patterns. The time course of SWD events is summarized in Figure $8 C$ and shows that administration of GBL to GA-treated ( $\square$ ) and sham-treated $(\square)$ animals induced typical paroxysmal SWDs in both groups with an increase in the duration of SWDs in the GA group during each $1 \mathrm{~min}$ segment $(p<0.05$ for the treatment effect, LMM). The total duration of SWD events was $30 \mathrm{~min}$ after GBL injections in the GA group and only $18 \mathrm{~min}$ in sham group $(p<0.001$ for the time effect, LMM). Figure $8 D$ demonstrates that the SWD latency onset after GBL injections was not statistically different between the two groups (sham: $97 \pm 17 \mathrm{~s}$; GA: $101 \pm 24 \mathrm{~s}, n=6, p>0.05, t$ 
A

GA

B

SHAM

Figure 8
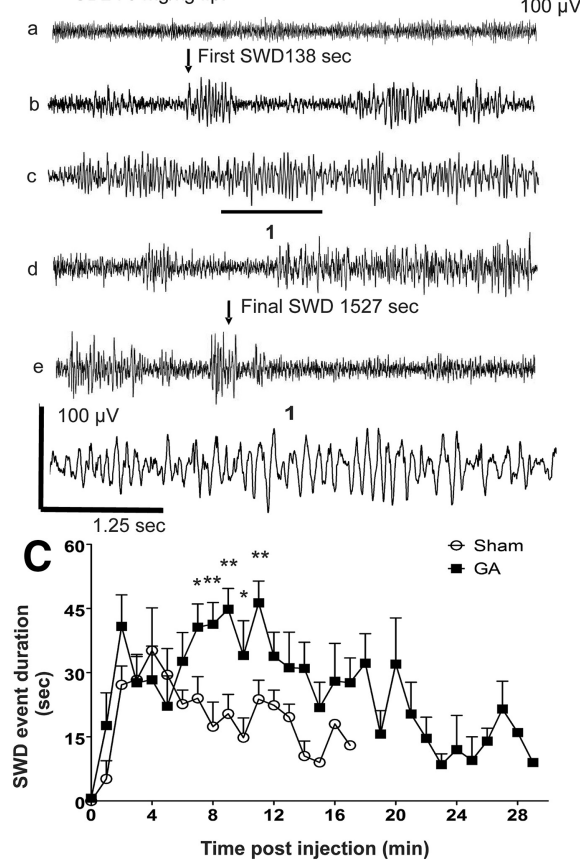

GBL $70 \mathrm{mg} / \mathrm{kg}$ i.p.
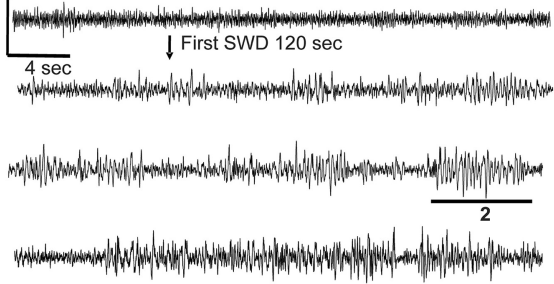

\ Final SWD $1031 \mathrm{sec}$

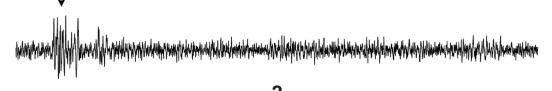

2

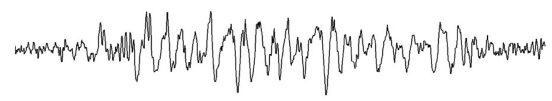

D

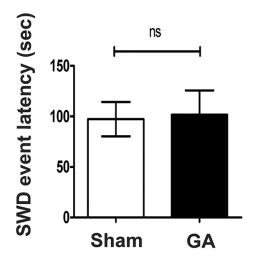

$\mathbf{E}$

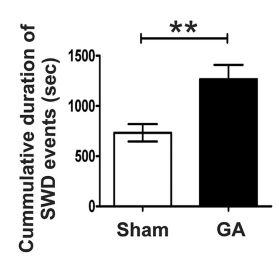

Figure 8. Rats exposed to GA at P7 display increased intensity of SWDs on EEG recordings in vivo. $A, B$, Original EEG recordings in vivo from a GA-treated rat $(\boldsymbol{A})$ and a sham-treated rat $(\boldsymbol{B})$. Lines a-e indicate progressive nonconsecutive EEG recordings following injections of $70 \mathrm{mg} / \mathrm{kg}$ (i.p.) GBL. Arrows indicate times of first and final SWD events following injections of GBL. Numbers next to the arrows indicate elapsed time (in seconds) from GBL injections. Calibration bars pertain to both panels. 1: The same segment of GA-treated GBL-induced SWD as labeled with a black horizontal bar in $A$ is shown on an expanded time scale. 2: The same segment of sham-treated GBL-induced SWD as labeled with a black horizontal bar in $\boldsymbol{B}$ is shown on an expanded time scale. Black square bars represent calibration that pertains to both panels 1 and 2. C, Graph represents an average time course of total SWD event duration per 1 min interval in GA-treated $(\square)$ and sham-treated $(\bigcirc)$ groups. There is a significant increase in SWD event duration per minute for the GA-treated group $\left(n=6\right.$ rats GA and Sham). ${ }^{*} p<0.05$ (Bonferroni posthoc comparison). ${ }^{* *} p<$ 0.01 (Bonferroni post hoc comparison). D, Quantification of the latency to the onset of first SWDs in sham ( $\square$ ) and GA groups $(\square)$ shows very little difference between the two groups: sham, $97 \pm 17 \mathrm{~s} ; \mathrm{GA}, 101 \pm 24 \mathrm{~s}$ ( $n=6$ rats). n.s., Not significant. $\boldsymbol{E}$, Cumulative SWD duration during the $30 \mathrm{~min}$ observation period was increased significantly in the GA-treated rats compared with the sham-treated rats by $\sim 40 \%$ ( 6 rats per group). ${ }^{* *} p<0.01$ ( $t$ test). Data were obtained from $6 \mathrm{GA}$-treated animals and 6 sham-treated animals. $\mathbf{C}-\boldsymbol{E}$, Symbols and bars represent mean values grouped by animal \pm SEM.

test). Cumulative SWD duration over all events during the 30 min observation period was significantly increased in the GAtreated group by $\sim 40 \%$ (Fig. $8 E$; sham: $733 \pm 86 \mathrm{~s}$; GA: $1267 \pm$ $143 \mathrm{~s}, p<0.01, t$ test). Together, these results suggest that hyperexcitable nRT neurons, as assessed by the preceding in vitro studies, may manifest as increased TC oscillations as measured by EEG in vivo.

Selective antagonism of T-channels reversed hyperexcitability of $\mathrm{nRT}$ neurons in vitro and diminished cumulative duration of SWD in GA-treated rats in vivo

It is well established that systemic administration of T-channel blockers in animals and humans can correct excessive excitability of TC networks and consequently will abolish GBL-induced SWDs and absence seizures (Beenhakker and Huguenard, 2009). Thus, we hypothesized that blocking T-channels may reverse chronic hyperexcitability of nRT neurons, which, in turn, may diminish hyperexcitability of intact TC circuits in vivo as determined by the intensity of GBL-induced SWDs. To address this issue, we took advantage of TTA-P2, a recently discovered selective and potent antagonist of T-channels. It has been shown previously that TTA-P2 blocks T-currents and LTCSs with negligible effect on tonic firing mode in $\mathrm{nRT}$ and TC neurons in brain slices from healthy rats (Dreyfus et al., 2010). However, its effects on baseline T-type "window" current, which represents a small number of channels that are available for activation at physiological membrane potentials (Dreyfus et al., 2010). In contrast to a previous study by Dreyfus et al. (2010), which found complete inhibition of burst firing with TTA-P2 in healthy rats, we found only partial inhibition of burst firing with TTA-P2 in GA-treated rats. This could be related to the slow on/off kinetics of TTA-P2 blockade of T-channels in GA-treated animals, slow diffusion of drug through the slice tissue, and/or shorter drug applications in our study. Inhibitory effects of TTA-P2 on the tonic firing mode in GA-treated rats in our study, but not in healthy rats (Dreyfus et al., 2010), could be related to our findings of upregulated T-currents in nRT cells from GA-treated rats. Toward this end, TTA-P2 inhibited strongly APs in the beginning of depolarizing pulse when T-channel are still operational, whereas later part of tonic firing mode was minimally affected (Fig. 9A). Furthermore, TTA-P2-induced hyperpolarization of membrane potential could have also contributed to the reduced AP frequency in tonic firing mode.

Based on the ability of TTA-P2 to reduce intrinsic excitability of $\mathrm{nRT}$ neurons in vitro, we reasoned that intraperitoneal injections of $5 \mathrm{mg} / \mathrm{kg}$ TTA-P2 may lead to reduced nRT activity in TC circuits of GA-treated rats and diminished responses to GBL in vivo as measured by EEG. Indeed, this expectation was confirmed 

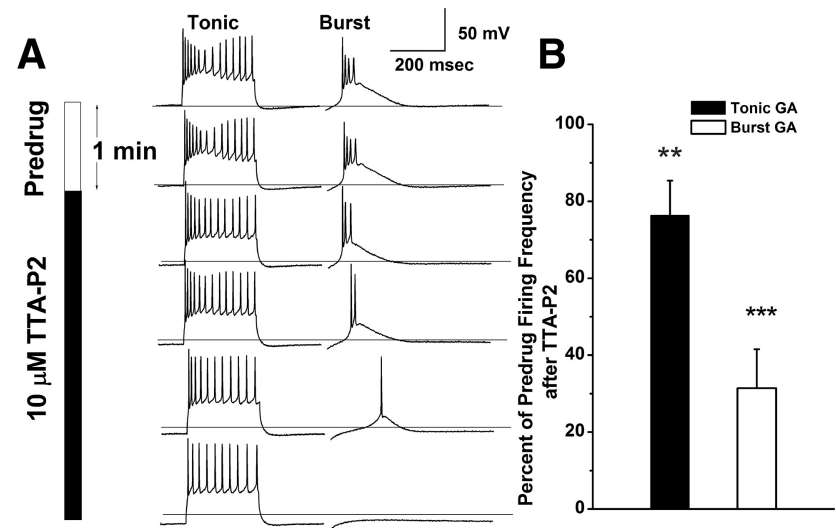

C

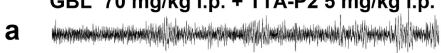
$58 \mathrm{sec}$

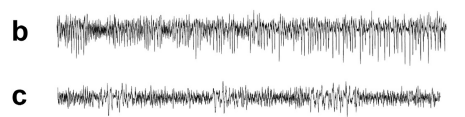

C $1920 \mathrm{sec}$

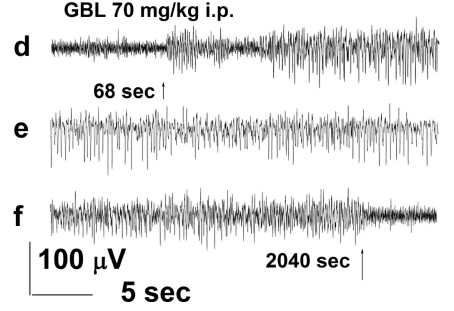

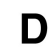

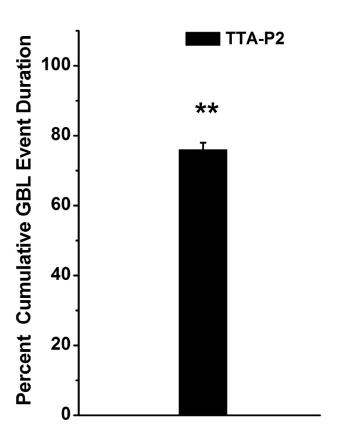

Figure 9. TTA-P2 reduces $\mathrm{nRT}$ neuron spike firing in vitro and attenuates pharmacologically induced SWDs of GA-exposed rats in vivo. A, Samples of original traces in GA-treated rats depict the progressive reduction in number of tonic APs from 14 to 10 mediated by bath application of $10 \mu \mathrm{m}$ TTA-P2; burst firing was completely inhibited in the same neuron. Dotted line indicates the natural RMP of this $\mathrm{nRT}$ neuron of $-60 \mathrm{mV}$. Tonic firing was evoked by $200 \mathrm{pA}$ current injection for $500 \mathrm{~ms}$; burst firing was evoked by a subsequent current injection of $-200 \mathrm{pA}$ for $500 \mathrm{~ms}$ in the same nRT neuron from the GA-treated group. White vertical bar on the left represents duration of predrug recording of $1 \mathrm{~min}$. Black vertical bar represents duration of TTA-P2 application of $5 \mathrm{~min}$. $\boldsymbol{B}$, Graph of average data shows that $10 \mu \mathrm{M}$ TTA-P2 reduced the tonic AP frequencies of $G A$-treated rats by $24 \pm 9 \%$, compared with predrug values in the same cells ( 12 neurons; ${ }^{* *} p<0.01$, paired $t$ test); burst firing was inhibited by $70 \pm 10 \%$ compared with predrug values $\left({ }^{* *} p<0.001\right.$, paired $t$ test). The number of APs was measured during 500 -ms-long depolarizing current injections of $200 \mathrm{pA}$ for tonic firing, and during 1.2-s-long period following hyperpolarized current injection of -200 pA for $500 \mathrm{~ms}$ for burst firing. All in vitro data presented in this figure were obtained from $12 \mathrm{GA}$-treated animals. C, Administration of $5 \mathrm{mg} / \mathrm{kg}$ TTA-P2 (i.p.) in vivo reduced the intensity of GBL-induced SWDs in GA-treated rats. Samples of representative nonconsecutive EEG traces in lines a-c depict the progression of GBL-mediated SWD events following pretreatment with intraperitoneal TTA-P2. Samples of nonconsecutive representative EEG traces in lines $d-f$ depict progression of control GBLmediated SWD events in the same GA-treated rat. Bars represent calibration. Short black arrows indicate baseline wake EEG followed by the onset of first GBL events. Long black arrows indicate final SWD events and return to awake EEG pattern. Numbers next to the arrows indicate elapsed time (in seconds) from GBL injections. $D$, Bar graph summarizes the average effect of TTA-P2 on cumulative duration of SWDs following GBL injections in GA-treated group that was normalized to the effect of GBL alone in the same animals ( $n=6$ rats). ${ }^{* *} p<0.01$ (paired $t$ test).

in representative EEG traces as shown in Figure $9 C$, which reveals diminished SWD discharges following injections of $5 \mathrm{mg} / \mathrm{kg}$ of TTA-P2 before administration of $70 \mathrm{mg} / \mathrm{kg}$ GBL (i.p.) in a rat exposed to GA at $\mathrm{P7}$ (traces a-c). In the same animal, we repeated the same dose of GBL injection $5 \mathrm{~h}$ later and found more robust, longer-lasting SWDs (traces $\mathrm{d}$ and e). Figure 9C (black short arrows) indicates initial SWD events, and Figure 9C (black long arrows) indicates final SWD events after GBL injections. With a pretreatment of TTA-P2, the overall cumulative duration of the

GBL response was decreased by $24 \pm 5 \%$ on average $(p<0.01$, paired $t$ test), as depicted in Figure $9 D$ (bar graph).

\section{Discussion}

Previous studies have shown that GA exposure at P7 produces persisting alterations in brain structure and function, including diminished long-term potentiation (Jevtovic-Todorovic et al., 2003) and decreased hippocampal inhibitory transmission (Sanchez et al., 2011). Even a single exposure of immature rodent brain to common GAs in vivo can increase apoptosis and diminish cognitive functioning later in life (Jevtovic-Todorovic et al., 2003; Boscolo et al., 2012). Importantly, GAs administered to young humans also may be detrimental to cognition later in life (Wilder et al., 2009). In the present study, we provide the first description of synaptic and intrinsic plasticity in nRT neurons after a single exposure to clinically relevant anesthetics during brain development. Exposure of P7 rat pups to an anesthesia combination mixture with midazolam, Iso, and $\mathrm{N}_{2} \mathrm{O}$ induces lasting alterations to inhibitory nRT synaptic properties, including decreased synaptic inhibition as demonstrated by diminished strength of eIPSCs, decreased decay $\tau$ s of eIPSCs, and decreased eIPSC PPR in nRT neurons. Long-term alterations of excitatory synapse properties include increased excitatory synaptic transmission as evidenced by increased strength in AMPA-mediated eEPSCs, as well as larger amplitudes of mEPSCs.

GA-mediated alterations in the biophysical properties and current density of T-channels in GA-exposed nRT neurons may account for the increase in both tonic and burst AP-firing properties. Consistent with these effects, we found increased severity of GBL-induced SWDs in intact TC circuits as measured by EEG recordings in GA-treated rats. Finally, we demonstrated that blocking T-channel function with TTA-P2 reversed hyperexcitability in $\mathrm{nRT}$ neurons in vitro and in intact TC networks in vivo. A parsimonious explanation of the changes in nRT neurons is that the changes could represent homeostatic plasticity. It is reasonable to envision that nRT neurons increase their activity to compensate for neuronal loss induced by GAs (Rizzi et al., 2008; Boscolo et al., 2012) to maintain balance in the circuitry. Naturally, every complex system, including neuronal networks, must have homeostatic mechanisms to maintain stability and survive. Unfortunately, this homeostatic plasticity can become maladaptive (reviewed for GABA receptors in Mody, 2005). Alternatively, GAs may affect directly the excitability of surviving nRT neurons. For example, it is well established that Iso potentiates $\mathrm{GABA}_{\mathrm{A}}$ receptor-mediated currents (Rudolph and Antkowiak, 2004), while it blocks T-currents, when measuring acute effects (Joksovic and Todorovic, 2010; Eckle et al., 2012). Thus, these acute effects may trigger an overexpression of T-channels and contrastingly may lead to a reduction in $\mathrm{GABA}_{\mathrm{A}}$ receptors as a dynamic response in the developing brain. Regardless of the mechanisms involved, it appears that synaptic and intrinsic plasticity in surviving $\mathrm{nRT}$ neurons in animals exposed in early life to GAs is maladaptive and contributes to chronic hyperexcitability of TC networks.

It is possible that other variables during exposure to GAs may contribute to the plasticity of synaptic transmission (e.g., hypoxia, hypoglycemia). We feel that alterations in these variables are extremely unlikely to explain the plasticity given that extensive previous studies have not demonstrated such events using exactly the same protocols (Jevtovic-Todorovic et al., 2003; Lu et al., 2006; Rizzi et al., 2008; Loepke et al., 2009). We used a triple combination of potent volatile anesthetic agents: $0.75 \mathrm{vol} \%$ Iso supplemented with 75 vol\% $\mathrm{N}_{2} \mathrm{O}$ and $9 \mathrm{mg} / \mathrm{kg}$ midazolam be- 
cause these agents often are used in combination in clinical anesthesia worldwide to provide hypnosis, analgesia, and amnesia, respectively; and a large body of literature exists from human and animal studies. We used age P7 for our experiments with single exposure to GA based on our previous study, which established that maximal GA-induced neurodegeneration in the thalamus occurs between ages P5 and P10 (Yon et al., 2005). Indeed, we found significant chronic alterations in both synaptic transmission and in T-currents in rats exposed to GAs at P7. It remains to be determined in future studies whether exposure to different GAs at different time points may have similar effects on synaptic and intrinsic plasticity in nRT neurons as well as on excitability of other components of TC circuitry, such as Ctx and TC relay neurons.

Our data strongly suggest that GA-induced changes are more prominent for AP-mediated than for AP-independent inhibitory synaptic transmission in nRT neurons. Decreased I-O curves of eIPSCs indicate that axonal recruitment is diminished in nRT neurons from GA-treated rats. It also is possible that GAs decrease spillover transmission via presynaptic mechanisms as suggested by alterations in PPR of eIPSCs. Strong synaptic stimulation and resulting multiquantal vesicular release may result in recruitment of many synaptic and extrasynaptic $\mathrm{GABA}_{\mathrm{A}}$ receptors in nRT neurons. This, in turn, may generate a slow tail (decay) of the eIPSCs. Thus, any decrease in AP-dependent presynaptic release of GABA may diminish probability of spillover and consequently decrease decay $\tau$ of eIPSCs in the postsynaptic membrane, whereas mIPSCs would not be affected. This possibility is supported by our previous finding showing that decreasing extracellular $\left[\mathrm{Ca}^{2+}\right]$ in healthy rats decreases amplitudes of eIPSCs and decreases decay $\tau$ in nRT neurons, effectively mimicking effects of exposure to GAs (Joksovic et al., 2009) (Fig. $1 C)$. Furthermore, inhibitory spillover transmission in the thalamus is well documented in TC relay neurons with slowly decaying eIPSCs $\tau$ s attributed to the expression of $\delta$-subunits of extrasynaptic $\mathrm{GABA}_{\mathrm{A}}$ receptors (Herd et al., 2013). It remains to be determined in future investigations whether similar mechanisms may operate in nRT neurons as well.

Our data with eEPCSs in sham animals are different from those of another study, which showed a smaller NMDA component of eEPSCs in nRT neurons from healthy rats (Gentet and Ulrich, 2004). Some possibilities include lower concentrations of $\mathrm{MgCl}_{2}$ in external solution in our study ( $0.5 \mathrm{~mm}$ vs $\left.1 \mathrm{~mm}\right)$, different strains of animals (our study used Sprague Dawley rats; the cited study used Wistar rats), different temperature of recordings (our study was done at room temperature; the other was done at $34^{\circ} \mathrm{C}-36^{\circ} \mathrm{C}$ ), and/or different stimulation protocols (our study used internal capsule stimulation; the other used local stimulation of layer VI Ctx neurons by application of $\mathrm{K}^{+}$).

Both human and animal studies have pointed to the potential role of $\mathrm{GABA}_{\mathrm{A}}$ receptor dysfunction and/or hyperactivity of thalamic T-channels in absence seizures (for review, see Beenhakker and Huguenard, 2009; Crunelli et al., 2012). It is of particular interest for this study that intra-nRT connections mediated by long-lasting eIPSCs are critical for regulating inhibitory output and phasic bursting activity. Thus, during TC oscillations, $\mathrm{GABA}_{\mathrm{A}}$-mediated inhibition of $\mathrm{nRT}$ neurons may prevent the pathological hypersynchrony of absence epilepsy, although intracortical mechanisms also may contribute (Steriade et al., 1990). Based on our findings that exposure of young rats to common GAs caused lasting loss of inhibitory function of nRT, as well as upregulation of T-currents and AMPA-mediated excitatory transmission, we propose that these animals may display in- creased propensity for absence seizures. Indeed, our experiments with in vivo measurements of GBL-induced SWDs strongly support this idea. The acute effects of GAs on the Ctx seizure-like EEG activity are already reported (Modica et al., 1990). To our knowledge, this is the first report that exposure to GAs can cause chronic effects upon SWDs in animals. Toward this end, another recent study found that exposure of P4-P6 rat pups to Iso or another volatile anesthetic, sevoflurane, also is associated with seizure-like Ctx EEG patterns and behavioral developmental deficits later in life (Seubert et al., 2013). Our data strongly suggest that exposure to GAs early in life may cause lasting dysfunction of TC circuitry later in life that possibly contributes to persisting cognitive changes. In a recent retrospective birth cohort study, Wilder et al. (2009) screened a large population of children exposed to GAs before the age 4 and found that they were at significant risk for the development of reading, written language, and math learning disabilities. Definitive clinical data on potential neurotoxic effects of GAs in humans still are lacking, and very little is known about possible long-term effects of GAs on thalamic signaling; but the question arises as to whether TC dysfunction after GAs may contribute to the cognitive disturbances in humans. It is well documented that thalamic hyperexcitability in humans may underlie disorders of cognition, sleep and wakefulness disorders, tinnitus, neurogenic pain, as well as absence epilepsy, collectively termed "TC dysrhythmias" (Llinás et al., 2005). New clinical studies are needed to establish whether "TC dysrhythmias" are more prevalent in patients exposed to GAs during critical periods of brain development. We postulate that alterations in the properties of $\mathrm{T}$-channels in concert with alterations in inhibitory and excitatory synaptic transmission contribute to the observed hyperexcitability of nRT neurons and that selective T-channel blockade may be used perioperatively to reverse nRT neuron hyperexcitability following exposure to GAs early in life. Hence, our studies may provide the rationale for new therapeutic strategies targeting thalamic ion channels to prevent or improve cognitive and other persisting dysfunctions after GA exposure.

\section{References}

Beenhakker MP, Huguenard JR (2009) Neurons that fire together also conspire together: is normal sleep circuitry hijacked to generate epilepsy? Neuron 62:612-632. CrossRef Medline

Bessaïh T, Bourgeais L, Badiu CI, Carter DA, Toth TI, Ruano D, Lambolez B, Crunelli V, Leresche N (2006) Nucleus-specific abnormalities of GABAergic synaptic transmission in a genetic model of absence seizures. J Neurophysiol 96:3074-3081. CrossRef Medline

Beyer B, Deleuze C, Letts VA, Mahaffey CL, Boumil RM, Lew TA, Huguenard JR, Frankel WN (2008) Absence seizures in $\mathrm{C} 3 \mathrm{H} / \mathrm{HeJ}$ and knockout mice caused by mutation of the AMPA receptor subunit Gria4. Hum Mol Genet 17:1738-1749. CrossRef Medline

Boscolo A, Starr JA, Sanchez V, Lunardi N, DiGruccio MR, Ori C, Erisir A, Trimmer P, Bennett J, Jevtovic-Todorovic V (2012) The abolishment of anesthesia-induced cognitive impairment by timely protection of mitochondria in the developing rat brain: the importance of free oxygen radicals and mitochondrial integrity. Neurobiol Dis 45:1031-1041. CrossRef Medline

Brambrink AM, Evers AS, Avidan MS, Farber NB, Smith DJ, Zhang X, Dissen GA, Creeley CE, Olney JW (2010) Isoflurane-induced neuroapoptosis in the neonatal rhesus macaque brain. Anesthesiology 112:834-841. CrossRef Medline

Crunelli V, Leresche N, Cope DW (2012) GABA-A receptor function in typical absence seizures. In: Jasper's basic mechanisms of the epilepsies, Ed 4 (Noebels JL, Avoli M, Rogawski MA, Olsen RW, Delgado-Escueta $\mathrm{AV}$, eds). Bethesda, MD: National Center for Biotechnology Information.

Dreyfus FM, Tscherter A, Errington AC, Renger JJ, Shin HS, Uebele VN, Crunelli V, Lambert RC, Leresche N (2010) Selective T-type calcium channel block in thalamic neurons reveals channel redundancy and physiological impact of IT window. J Neurosci 30:99-109. CrossRef Medline 
Eckle VS, Digruccio MR, Uebele VN, Renger JJ, Todorovic SM (2012) Inhibition of T-type calcium current in rat thalamocortical neurons by isoflurane. Neuropharmacology 63:266-273. CrossRef Medline

Galbraith S, Daniel JA, Vissel B (2010) A study of clustered data and approaches to its analysis. J Neurosci 30:10601-10608. CrossRef Medline

Gentet LJ, Ulrich D (2004) Electrophysiological characterization of synaptic connections between layer VI cortical cells and neurons of the nucleus reticularis thalami in juvenile rats. Eur J Neurosci 19:625-633. CrossRef Medline

Herd MB, Brown AR, Lambert JJ, Belelli D (2013) Extrasynaptic GABA receptors couple presynaptic activity to postsynaptic inhibition in the somatosensory thalamus. J Neurosci 33:14850-14868. CrossRef Medline

Jevtovic-Todorovic V, Olney JW (2008) PRO: anesthesia-induced developmental neuroapoptosis: status of the evidence. Anesth Analg 106:16591663. CrossRef Medline

Jevtovic-Todorovic V, Hartman RE, Izumi Y, Benshoff ND, Dikranian K, Zorumski CF, Olney JW, Wozniak DF (2003) Early exposure to common anesthetic agents causes widespread neurodegeneration in the developing rat brain and persistent learning deficits. J Neurosci 23:876-882. Medline

Joksovic PM, Todorovic SM (2010) Isoflurane modulates excitability of the nucleus reticularis thalami in vitro. Ann N Y Acad Sci 1199:36-42. CrossRef Medline

Joksovic PM, Weiergräber M, Lee W, Struck H, Schneider T, Todorovic SM (2009) Isoflurane-sensitive presynaptic R-type calcium channels contribute to inhibitory synaptic transmission in the rat thalamus. J Neurosci 29:1434-1445. CrossRef Medline

Khosravani H, Zamponi GW (2006) Voltage-gated calcium channels and idiopathic generalized epilepsies. Physiol Rev 863:941-966. CrossRef Medline

Lacey CJ, Bryant A, Brill J, Huguenard JR (2012) Enhanced NMDA receptor-dependent thalamic excitation and network oscillations in stargazer mice. J Neurosci 32:11067-11081. CrossRef Medline

Llinás R, Urbano FJ, Leznik E, Ramírez RR, van Marle HJ (2005) Rhythmic and dysrhythmic thalamocortical dynamics: GABA systems and the edge effect. Trends Neurosci 28:325-333. CrossRef Medline

Loepke AW, Istaphanous GK, McAuliffe JJ 3rd, Miles L, Hughes EA, McCann JC, Harlow KE, Kurth CD, Williams MT, Vorhees CV, Danzer SC (2009) The effects of neonatal isoflurane exposure in mice on brain cell viability, adult behavior, learning, and memory. Anesth Analg 108:90-104. CrossRef Medline

Lu LX, Yon JH, Carter LB, Jevtovic-Todorovic V (2006) General anesthesia activates BDNF-dependent neuroapoptosis in the developing rat brain. Apoptosis 11:1603-1615. CrossRef Medline
Modica PA, Tempelhoff R, White PF (1990) Pro- and anticonvulsant effects of anesthetics (Part I). Anesth Analg 70:303-315. Medline

Mody I (2005) Aspects of the homeostatic plasticity of $\mathrm{GABA}_{\mathrm{A}}$ receptormediated inhibition. J Physiol 562:37-46. CrossRef Medline

Paz JT, Bryant AS, Peng K, Fenno L, Yizhar O, Frankel WN, Deisseroth K, Huguenard JR (2011) A new mode of corticothalamic transmission revealed in the $\mathrm{Gria}^{-1-}$ model of absence epilepsy. Nat Neurosci 14:11671173. CrossRef Medline

Rizzi S, Carter LB, Ori C, Jevtovic-Todorovic V (2008) Clinical anesthesia causes permanent damage to the fetal guinea pig brain. Brain Pathol 18:198-210. CrossRef Medline

Rudolph U, Antkowiak B (2004) Molecular and neuronal substrates for general anesthetics. Nat Neurosci 5:709-720. CrossRef Medline

Sanchez V, Feinstein SD, Lunardi N, Joksovic PM, Boscolo A, Todorovic SM, Jevtovic-Todorovic V (2011) General anesthesia causes long-term impairment of mitochondrial morphogenesis and synaptic transmission in developing rat brain. Anesthesiology 115:992-1002. CrossRef Medline

Seubert CN, Zhu W, Pavlinec C, Gravenstein N, Martynyuk AE (2013) Developmental effects of neonatal isoflurane and sevoflurane exposure in rats. Anesthesiology 119:358-364. CrossRef Medline

Sherman SM (2005) The role of the thalamus in cortical function: not just a simple relay. Thalamus Relat Syst 3:205-216. CrossRef

Snead OC 3rd (1988) Gamma-hydroxybutyrate model of generalized absence seizures: further characterization and comparison with other absence models. Epilepsia 29:361-368. Medline

Steriade M, Jones EG, Llinás RR (1990) Thalamic oscillations and signaling. New York: Wiley.

Wilder RT, Flick RP, Sprung J, Katusic SK, Barbaresi WJ, Mickelson C, Gleich SJ, Schroeder DR, Weaver AL, Warner DO (2009) Early exposure to anesthesia and learning disabilities in a population-based birth cohort. Anesthesiology 110:796-804. CrossRef Medline

Yon JH, Daniel-Johnson J, Carter LB, Jevtovic-Todorovic V (2005) Anesthesia induces neronal cell death in the developing rat brain via the intrinsic and extrinsic apoptotic pathways. Neuroscience 135:815-827. CrossRef Medline

Zaman T, Lee K, Park C, Paydar A, Choi JH, Cheong E, Lee CJ, Shin HS (2011) CaV2.3 channels are critical for oscillatory burst discharges in the reticular thalamus and absence epilepsy. Neuron 70:95-108. CrossRef Medline

Zou X, Liu F, Zhang X, Patterson TA, Callicott R, Liu S, Hanig JP, Paule MG, Slikker W Jr, Wang C (2011) Inhalation anesthetic-induced neuronal damage in the developing rhesus monkey. Neurotoxicol Teratol 33:592597. CrossRef Medline

Zucker RS, Regehr WG (2002) Short-term synaptic plasticity. Annu Rev Physiol 64:355-405. CrossRef Medline 